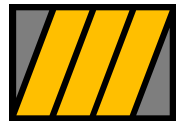

ESCUELA DE NEGOCIOS Universidad Torcuato Di Tella

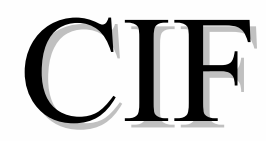

Centro de Investigación en Finanzas

Documento de Trabajo 07/2005

\title{
Global Factors and Emerging Market Spreads
}

\author{
Martín González Rozada \\ UTDT \\ and \\ Eduardo Levy Yeyati \\ UTDT and IDB
}




\title{
Global Factors and Emerging Market Spreads ${ }^{1}$
}

\author{
Martín González Rozada \\ UTDT \\ Eduardo Levy Yeyati \\ UTDT and IDB
}

December 2005

\begin{abstract}
This paper shows that a large fraction of the variability of emerging market bond spreads is explained by the evolution of global factors such as risk appetite (as reflected in the spread of high yield corporate bonds in developed markets), global liquidity (measured by the international interest rates) and contagion (from systemic events like the Russian default). This link has remained relatively stable over the history of the emerging market class, is robust to the inclusion of country-specific factors, and helps provide accurate long-run predictions. Overall, the results highlight the critical role played by exogenous factors in the evolution of the borrowing cost faced by emerging economies.
\end{abstract}

JEL Classification Numbers: F34, E43, G15

Keywords: Sovereign Spreads, Risk Appetite, Global Liquidity, Emerging Markets

\footnotetext{
${ }^{1}$ Martin Gonzalez Rozada gratefully acknowledges financial aid from the IADB. The authors would like to thank Jorge Morgenstern and Sebastián Castresana for excellent research assistance and participants at the RES brown bag seminar at the IADB for useful comments. The usual disclaimers apply.
} 


\section{Introduction}

Global (exogenous) factors are increasingly seen as key determinants of the borrowing costs of emerging economies, for good reasons. In principle, the pricing of debt issued by financially integrated emerging economies should be no different from the pricing of non-investment grade securities in general, and low-grade bonds in developed economies in particular. Both should reflect the level of risk of the security, and a risk premium (the price of risk) that is, in turn, a reflection of the risk aversion or, alternatively, risk appetite- of the international investor. It follows that variation in emerging market spreads may be driven by exogenous changes in global risk appetite. ${ }^{2}$ In addition, global liquidity influences the international cost of capital and, to the extent that this cost affects debt sustainability, also emerging market spreads. It follows that an important part of the variability of emerging spreads could be seen as a reflection of exogenous factors (such as the international business cycle) that simultaneously determine both risk appetite and the interest rate.

This paper examines this premise empirically. Specifically, it studies the extent to which changes interest rates and bond spreads in developed countries explain the variability of emerging market spreads in recent years. More precisely, based on high frequency (daily, weekly and monthly) data, it estimates panel error-correction models of emerging spreads on high-yield spreads and international rates, controlling for country specific variability (using credit ratings as a proxy for country-specific risk or, alternatively, country-month dummies) as well as for the presence of contagion. ${ }^{3}$

The main empirical findings are the following:

i. Risk appetite, proxied by high-yield spreads in developed markets, is a key determinant of the (long- and short-run) evolution of emerging market spread. While the link exhibits a break by late 1999, it is nonetheless surprisingly strong over the whole life of the emerging market class.

ii. International liquidity (proxied by the US Treasury notes, 10 year constant maturity yield) exhibits a significant benign influence on the long-run levels of emerging spreads.

\footnotetext{
${ }^{2}$ Indeed, this intuition has already been noted in the literature. See, e.g., Grandes (2003), Herrera and Perry (2002), Calvo and Talvi (2004) and, particularly, García Herrero and Ortiz (2004).

${ }^{3}$ By contagion we understand cases in which a crisis elsewhere negatively affects an economy with neither real ties with the crisis country nor a visible deterioration in fundamentals (Mexico 1994 and Russia 1998 are the two episodes for which we control in the tests).
} 
iii. These two exogenous factors explain around 30 percent of the long-run (dynamic) variability of emerging market spreads (between 15 and 23 percent for the short-run using weekly and monthly data, respectively).

iv. Contagion from crisis with systemic effects (as exemplified by the 1998 Russian default) exerts a strong negative impact on spreads.

v. The results are relatively stable over the period under analysis (1994-2005, corresponding to the existence of the emerging market debt class), although the link strengthens slightly after 1999.

vi. Each of these results is robust to the introduction of additional variables, including countrymonth controls to proxy available information about macro fundamentals, and credit ratings.

These findings have several potentially important implications for the emerging markets literature. First, they show that variations in emerging market spreads can be largely explained by exogenous factors. In this way, the paper contributes to the discussion about the nature of emerging market stability, specifically on the degree of exogeneity in the determination of the highly volatile borrowing costs faced by emerging economies - a major source of financial distress in the recent past. Moreover, it shifts the discussion on debt dynamics from sustainability to vulnerability, as it emphasizes the exogenous component of external volatility, placing the focus on the factors that would make a country more or less resilient to sudden changes in the external context. The exogenous nature of borrowing costs highlights the role of country-specific fundamentals as determinants of the exposure to external shocks -rather than as the drivers of borrowing costs as proposed by the standard view of debt sustainability. In addition, the findings shed new light on the connection between the borrowing costs faced by emerging economies and the cycle in the industrial world (as captured by international interest rates), a link already noted in the early literature on capital flows. ${ }^{4}$ In passing, the paper documents that, contrary to conventional wisdom, credit ratings respond to spreads more than they influence them, casting doubt on their informational content.

The paper proceeds as follows. The next section introduces the reduced-form model that underlies the empirical specification of our tests, presents the data and describes the empirical methodology. Section III reports the main empirical findings and robustness tests. Section IV concludes.

\footnotetext{
${ }^{4}$ See, i.a., Calvo et al (1993), and Levy Yeyati and Sturzenegger (2000).
} 


\section{Emerging market and corporate bond pricing}

\section{A reduced-form model}

Interest rate arbitrage by risk-averse investors implies that

$$
(1-q)(1+r)+q V=\left(1+r_{f}\right)+\varphi q
$$

where $q$ is the probability of default, $V$ the recovery value after default, $r$ and $r_{f}$ the interest rates charged to the bond and to a risk-free asset of similar duration, and $\varphi$ is a parameter that reflects investors' risk aversion. Then, we can express the emerging market spread as:

$$
\text { spread } \equiv r-r_{f}=\left[\varphi+\left(1+r_{f}\right)-V\right][q /(1-q)]
$$

or, more generally, assuming that recovery values are stable over time and comparable across bonds, as

$$
\text { spread }_{i t}=\rho\left(r_{t}^{f}, \varphi_{t}\right) \theta\left[q\left(X_{i t}\right)\right] \phi_{i}\left(r_{t}^{f}, d_{t}^{c}\right),
$$

where

- $\quad \rho$ denotes the price of credit risk, which depends on the international risk-free rate $r_{t}^{f}$ and risk aversion $\varphi_{t}$

- $\theta$ measures the incidence of the default risk of the issuer, $q$, itself a function of country-specific (in the case of sovereign debt) or firm-specific (in the case of corporate bonds) fundamentals $X_{i r} ;$ and

- $\phi_{i}$ is a scale factor reflecting global factors that affect corporate and emerging market debt differently, such as global liquidity (measured by the international risk-free rate $r_{t}^{f}$ ) and episodes of global financial distress (represented by the dummy $d_{t}^{c}$ ), which we assume to be such that $\phi_{i}\left(r_{t}^{f}, \mathrm{~W}_{t}\right)=\left(r_{t}^{f}\right)^{\alpha j} \exp \left(\beta_{j} d_{t}^{c}\right)$.

In particular, we have that 


$$
\ln H Y_{t}=\ln \rho\left(r_{t}^{f}, \varphi_{t}\right)+\ln \theta\left[q\left(H Y_{t}\right)\right]+\alpha H Y \ln r_{t}^{f}+\beta_{H Y} d_{t}^{c}
$$

where $H Y_{t}$ is a High Yield spread index (the weighted average spread of high-yield corporate debt around the world) and $q(H Y)$ stands for the associated (weighted average) credit risk, from which we can obtain a good approximation of the log of the price of risk as

$$
\ln \rho\left(r_{t}^{f}, \varphi_{t}\right)=\ln \left(H Y_{t}\right)-\ln \theta\left[q\left(H Y_{t}\right)\right]-\alpha_{H Y} \ln r_{t}^{f}-\beta_{H Y} d_{t}^{c}
$$

to characterize emerging market spreads as:

$$
\ln e m b i_{i t}=\ln H Y_{t}+\ln \theta\left[q\left(e m b i_{i t}\right)\right]-\ln \theta\left[q\left(H Y_{t}\right)\right]+\alpha \ln r_{t}^{f}+\beta_{H Y} d_{t}^{c}
$$

where $\alpha=\alpha_{e m b i}-\alpha_{H Y}$, and $\beta=\beta_{e m b i}-\beta_{H Y}$ Moreover, assuming for the moment that, in both cases, idiosyncratic credit risk is reasonably captured by the credit rating of the issuer (we relax this assumption below), so that $\ln \theta\left[q\left(X_{i t}\right)\right] \approx \gamma \ln$ rating $_{i t}$, and that rating ${ }_{H Y}$ remains relatively stable over time, we obtain the following long-run specification:

(7) $\quad \ln e m b i_{i t}=\ln H Y_{t}+\alpha \ln r_{t}^{f}+\beta_{H Y} d_{t}^{c}+\gamma \ln$ rating $_{i t}$

Note that the price of risk captured by the high yield spread is a function both of risk appetite and the risk-free rate. On the other hand, international interest rates may also influence the pricing of sovereign and corporate risk due to international arbitrage: to the extent that it reflects investment returns in the developed world, it is expected to affect negatively the sustainability of emerging market debt and its investor base relative to other risky securities.

There are reasons to expect that the adjustment to changes in its main determinants would not be immediate (for example, imperfect information or market frictions may introduce costs that require that deviations from the long-run level exceeds a minimum - possibly asymmetric- threshold to trigger a price adjustment). While we are primarily concerned about the determination of emerging market spreads in the long-run, to provide a complete characterization of the impact of global factors we also 
examine the reaction to short-run deviations, and the speed of convergence to the long-run level, by augmenting the previous long-run specification with an error correction equation.

\section{The data}

To proxy for the price of risk, we use Credit Swiss First Boston's High Yield Index (HY), which measures the spread over the US treasuries yield curve at the redemption date with the worst yield -an alternative measure of high yield spreads prepared by J. P. Morgan yielded almost identical results. Emerging market sovereign spreads are measured as the spread over Treasuries of J. P. Morgan's EMBI_Global index (embi) for each of the 33 emerging economies included in the Global portfolio (period coverage varies across countries, as reported in Appendix Table A2). The credit rating variable (rating) is constructed based on Standard \& Poor's rating for long-term debt in foreign currency. As a proxy for international liquidity, we use the 10-year US Treasury rate (10YT), although we also run tests using the US\$ and the DM/Euro 6-month LIBOR for robustness (sourced from the Federal Reserve and the BBA, respectively). Also for robustness, as an alternative measure of the price of risk, we test the volatility implicit in US stock options (VIX) compiled by the Chicago Board Options Exchange. In all cases, we work alternatively with monthly, weekly and (occasionally) daily data.

\section{The methodology}

The econometric model used in this paper describes a basic long-run relationship between the market spreads, the high yield index and the international rate. The first step in analyzing this equilibrium relationship is to check the individual statistical properties of the panel data series. This is done using different panel data unit roots tests as explained below. If the variables in the specific long run equation have unit roots, the second step consists in verifying the existence of a long run equilibrium relationship using panel cointegration tests. If there is panel cointegration, then the next step is to estimate the parameters of the model.

To analyze the statistical properties of each individual panel data series we performed two types of panel unit root tests: Maddala and Wu (1999) and Choi (2001). All these tests are based on variations of a standard autoregressive process of order one for panel data. Maddala and Wu use an alternative 
approach to panel unit root tests based on Fisher's (1932) results. We report, for this test, the asymptotic $\chi_{2 N}^{2}$ statistic using augmented Dickey-Fuller individual unit root tests. Choi proposes a similar standardized statistic as Maddala and Wu, but with a standard normal asymptotic distribution.

Table 2 shows the results of these panel unit root tests for all individual variables in the long run equilibrium relationships for both the monthly (Panel A) and weekly (Panel B) dataset.

It is clear from the table that all variables individually have a panel unit root using standard statistical levels of significance. It follows that, if there exists any meaningful relationship between the market spreads and the high yield index, it should be because they are co-integrated. To explore this possibility we follow Engle and Granger approach and performed panel unit root tests on the residuals of the cointegration relationship. Table 2 also shows these results. As it can be seen from the table, both tests reject the null of panel unit root.

Since, there is evidence of co-integration, by the Granger Representation Theorem, the variables in the long run equilibrium relationship have a panel error correction representation (PECM). This representation expresses the model in levels and differences in order to separate out the long-run and short-run effects. We use the Engle-Granger methodology (Engle and Granger, 1987) to estimate the PECM. This methodology is a two-stage modeling strategy which may be formalized as follows. Stage one, estimate the long-run parameters of the cointegration equation using a least squares dummy variable (LSDV) procedure

$$
\ln \left(\mathrm{embi}_{\mathrm{it}}\right)=\alpha_{0 \mathrm{i}}+\alpha_{1} \ln \left(\mathrm{HY}_{\mathrm{t}}\right)+\alpha_{2} \ln \left(r_{t}^{f}\right)+\alpha_{3} \ln \left(W_{t}\right)+\alpha_{4} \ln \left(\text { rating }_{i t}\right)+\varepsilon_{i t}
$$

where $X_{t}$ is a vector of variables that could include some measure of credit rating, the international interest rate, etc. The estimators in this first step are consistent even when some or all the variables in the right hand side of the equation are endogenous because the estimates of the parameters converge to their probability limits at a rate of $\mathrm{T}$ instead of at the usual asymptotic rate of $\mathrm{T}^{1 / 2}$. From equation

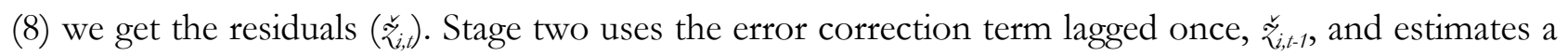
PECM to get the short-run dynamics. Out of the steady state we do not know the lag structure of the short term dynamics, therefore we begin with a general specification of the form 


$$
\begin{aligned}
\Delta \ln \left(\mathrm{embi}_{i, t}\right) & =\gamma_{0 \mathrm{i}}+\gamma_{1} \breve{\mathrm{z}}_{\mathrm{i}, \mathrm{t}-\mathrm{l}}+\sum_{\mathrm{j}=0}^{\mathrm{p}} \Gamma_{0 j} \Delta \ln \left(\mathrm{HY}_{\mathrm{t}-\mathrm{j}}\right)+\sum_{\mathrm{j}=0}^{\mathrm{q}} \Gamma_{1 j} \Delta \ln \left(r_{t-j}^{f}\right)+\sum_{\mathrm{j}=0}^{\mathrm{m}} \Gamma_{2 j} \Delta \ln \left(W_{t-j}\right)+ \\
& +\sum_{\mathrm{j}=0}^{\mathrm{n}} \Gamma_{3 j} \Delta \ln \left(\operatorname{rating}_{i, t-j}\right)+\sum_{\mathrm{j}=1}^{\mathrm{r}} \Gamma_{4 j} \Delta \ln \left(\mathrm{embi}_{i, t-j}\right)+u_{i t}
\end{aligned}
$$

We estimate this model using the LSDV approach. We are aware that this is not the most efficient way to do it, because the lagged dependent variable appears as explanatory variable in the model, but since our sample size is much larger in the time series dimension than in the cross section one we basically are assuming that the time dimension is large enough such that the estimation bias goes to zero.

\section{Empirical results}

\section{Main results}

At first sight, the data appears to support the view that global factors exert a strong influence on emerging market spreads. Figure 1 illustrates the point, presenting the median of individual EMBI spreads at each point in time, and the distribution around its cross-section mean (all variables normalized by their country-specific means), together with our two main proxies of global factors. ${ }^{5} \mathrm{~A}$ simple comparison of the first two panels shows that high yield spreads in developed and developing countries (HY and embi) have indeed moved together over the last 10 years -somewhat less so in the earlier period due to the strong impact of contagion from the Mexican and Russian crises. Moreover, there seems to be also a direct relationship between the emerging markets spreads and international liquidity, measured through the US Treasury notes, 10 year constant maturity yield, as showed by a statistically significant correlation coefficient of about 0.12 .

This first impression is strongly confirmed by more rigorous estimates. Table 3 reports our baseline specification and our main results. Column 1 shows the estimated long-run equation of the spread as a function the high yield index, the international interest rate, contagion from crises abroad, and the credit rating, using monthly data. As can be seen, the correlation is large and highly significant for all the variables. In particular, two exogenous global factors $H Y$ and $10 Y T$ explain about 30\% of the

\footnotetext{
5 The composite EMBI index typically used as a crude measure of emerging market risk pools together individual country portfolios of diverse duration and risk, and may be too sensitive to big outliers (highly indebted countries undergoing a crisis). Hence, our focus is on the distribution.
} 
dynamic (within) variability of spreads, (37\% if we add contagion to the list), while the inclusion of credit ratings brings this number to close to $60 \%$. The short-run equation is also consistent with our priors (column 2). All variables have a strong contemporaneous impact on spreads but no delayed effect, and roughly $7 \%$ of deviations from the long run level are eliminated per month, so that the average lag length is about fourteen months. Weekly data tell the same story (columns 3 and 4): high correlation, strong explanatory power (about 60\% of dynamic variability), and fast convergence (roughly 33 weeks).

Note that the influence of the international interest rate goes beyond the standard arbitrage view that indicates that portfolio flows respond to increases in the international rate (Calvo et al., 1993). Indeed, the evidence that sovereign spreads adjust close to one to one to changes in the foreign rate implies that borrowing costs in emerging economies respond more than proportionally to the interest rate cycle in the developed world. ${ }^{6}$

\section{Robustness I: Global factors then and now}

A natural question regarding the connection between bond pricing in developed and developing countries is whether it changed (and, in particular, strengthened) over the years, due to the growing familiarity with the emerging market asset and the increasing integration of capital markets (and bondholders). In this section we analyze this aspect by looking at possible structural breaks in the long run equilibrium relationship. In particular, we study whether the coefficient of $H Y$ changes over time.

The specification of the test is standard. Starting from the following long-run equilibrium relationship

$$
\ln \left(\mathrm{embi}_{\mathrm{it}}\right)=\alpha_{0 \mathrm{i}}+\alpha_{1} \ln \left(\mathrm{HY}_{\mathrm{t}}\right)+\beta \ln \left(X_{i t}\right)+\varepsilon_{i t}
$$

where $X_{t}$ is a vector including all variables in our baseline regression. We would like to consider a possible break in the $a_{1}$ coefficient at an unknown date $k$. Under the null hypothesis of no break, the alternative hypothesis implies that:

\footnotetext{
${ }^{6}$ The USD and the DM/Euro LIBOR (both correlated with 10YT) yield comparable results (omitted here for conciseness and available from the authors on request).
} 
$H_{1}:\left\{\begin{array}{lr}\alpha_{1, k}{ }^{a} & \text { for } t=1,2, \ldots, k \\ \alpha_{1, k}{ }^{b} & \text { for } t=k+1, k+2, \ldots, T\end{array}\right.$

so that equation (9) can be written as:

(9') $\quad \ln \left(\mathrm{embi}_{\mathrm{it}}\right)=\alpha_{0 \mathrm{i}}+\alpha_{1, k}{ }^{a} \ln \left(\mathrm{HY}_{\mathrm{t}}\right) \mathrm{I}(\mathrm{t} \leq \mathrm{k})+\alpha_{1, k}{ }^{b} \ln \left(\mathrm{HY}_{\mathrm{t}}\right) \mathrm{I}(\mathrm{t}>\mathrm{k})+\beta \ln \left(X_{i t}\right)+\varepsilon_{i t}$

The Wald test statistic for these hypotheses is defined as

$W(k)=\frac{\left(\hat{\alpha}_{1, k}{ }^{a}-\hat{\alpha}_{1, k}{ }^{b}\right)^{2}}{\operatorname{Var}\left(\hat{\alpha}_{1, k}{ }^{a}-\hat{\alpha}_{1, k}{ }^{b}\right)}$

We plot $W(k)$ for all possible break dates $k$. As it is usual in the literature of endogenous breaks, for the determination of the possible break dates we truncate the sample to exclude the top and bottom 15\% of the observations. The OLS change-point estimation is given by

$\hat{k}=\underset{k}{\operatorname{Arg} \max } W(k)$

Figure 2 shows the Wald tests for the long-run equilibrium relationship presented in column (1) of Table 3 using monthly data. From the figure we can see that the OLS estimation of the break date is September 1999 (marked with a vertical line). ${ }^{7}$ Using this break point the long-run equilibrium relationship under the alternative hypothesis is:

\footnotetext{
${ }^{7}$ Reassuringly, when we compute the same exercises using the weekly dataset we obtain the second week of January 2000 as the new cut-off date.
} 


$$
\begin{aligned}
\ln \left(\mathrm{embi}_{\mathrm{it}}\right)= & 2.1030+1.0074 \ln \left(\mathrm{HY}_{\mathrm{t}}\right) \mathrm{I}(\mathrm{t} \leq 1999: 9)+0.9402 \ln \left(\mathrm{HY}_{\mathrm{t}}\right) \mathrm{I}(\mathrm{t}>1999: 9)- \\
& (4.45)(20.39) \\
- & 1.5094 \ln \left(\text { Rating }_{i t}\right)+0.6351 \ln \left(10 Y T_{t}\right)+0.2709 \text { Contagion Rusia }_{i t} \\
& (-8.58) \\
+ & 0.1252 \text { Contagion }_{\text {Mexico }}
\end{aligned}
$$

where the numbers in parentheses are the individual coefficients t-statistics.

Two important conclusions can be drawn from these exercises. First, although the explanatory power of global factors is higher in the later period (when they explain about 50 percent of the within variability), their effect is not circumscribed to the later period. Thus, rather than a recent phenomenon, the connection appears to have been relevant since the beginning of emerging market debt as an asset class -with only a minor strengthening (as measured by its explanatory power) that appears to coincide with the aftermath of the Russian crisis. This latter point is revealed by the robustness tests reported in Table 4. There, guided by our previous results, we split the monthly sample into two sub-samples (1993-1999, and 2000-2005) and rerun the regressions in columns (1)-(2) in Table 3. The results, presented in columns (1) to (4), clearly show that, while the HY coefficients (both in the short- and long-run equation) are larger for the earlier period, their explanatory power is comparable (and increases for the long-run equation) in the later years. These findings are confirmed when we replicate the exercise for the full sample and control the effect on the later period using an interaction of $\mathrm{HY}$ variables with a period dummy (columns 5 and 6).

Given that emerging economies entered the EMBI portfolio at different points in time, it is natural to ask whether the parameter change documented above is simply due to the combination of crosscountry differences and a changing sample composition. To dispel these doubts, we replicate columns (1) to (4) for a balanced sample, focusing on three Latin American countries that have been in the emerging market class since the very beginning and that have historically represented a large portion of the whole emerging market portfolio: Argentina, Brazil and Mexico (see columns 7 to 10). The messages for this balanced sample are surprisingly consistent with the previous one: a strong impact of global factors throughout the sample, with HY exhibiting increasing explanatory power over the years. At any rate, while the incidence of global factors is not specific of a particular time, in light of the previous results, in what follows we restrict our attention on the later period. 


\section{Robustness II: Asymmetries}

Conventional wisdom would indicate that, while emerging spreads tend to decline only gradually, they go up in a rush. In fact, this asymmetry is readily verified by a cursory look at the distribution of monthly changes (Table A3), which in most cases exhibits positive skewness coefficients.

Accordingly, one should observe this fact reflected in the short-run portion of our baseline specification, to the extent that the variables included there explain a major share of the variability of spreads. Is the elasticity of emerging market spreads to changes in global conditions the same irrespective of the sign of the change? Is the effect of a rating upgrade comparable to that of a rating downgrade?

The evidence, summarized in Table 5, provides mixed answers. Columns (1) and (3) reproduce the long-run estimates for ease of comparison. As can be seen from the short run equation in column (2) emerging spreads react more rapidly to increases in risk aversion than to declines. For monthly data, a 100 percent increase in $H Y$ raises the average emerging spread by 105 percent, while a comparable decline in $H Y$ only reduces the emerging spread by 47 percent. But, using weekly data, column (4), one can see that emerging spreads react in the same way to increases or declines in risk aversion. The F tests presented in columns (2) and (4) show that the effect of changes in global liquidity and credit ratings does not display a statistically significant asymmetry. Finally, the estimates indicate a faster speed of convergence for downward deviations (about four months and a half or ten weeks, using monthly and weekly data respectively), again in line with the view that negative shocks (e.g., increases in risk appetite or credit downgrades) are reflected in spreads more rapidly than positive ones. This evidence suggests that the average lag length of about fourteen months estimated by our baseline regression is strongly affected by the upward deviations from the long run equilibrium.

\section{Robustness III: The VIX as an alternative measure of the price of risk}


The economic literature and the financial markets have identified the VIX (a measure of the volatility implied in the pricing of options on US stocks) as an indicator of investor risk appetite. ${ }^{8}$ While, in our view, this index should reflect the (time-varying) systemic volatility in the stock market along with variations in risk appetite and, as such, should be an inferior thermometer of the latter, it is nonetheless an interesting measure of exogenous global factors and an opportunity to assess the robustness of our previous results. Moreover, as Figure 3 illustrates, it is strongly correlated with HY (the coefficient is above $50 \%$ and highly significant), which lends support to the view that, to certain degree, it may be capturing some of the same aspects.

Table 6 provides reassuring results on both fronts. The first two columns report the baseline longand short-run regressions, substituting the VIX for the HY index. The results are broadly comparable to those in Table 3, with only a somewhat weaker explanatory power. Indeed, when we include both indexes simultaneously, the HY appears part of the influence of VIX on the behavior of spreads for the weekly sample (columns (7) and (8)), and most of it for the monthly sample (where the VIX coefficient declines visibly and ceases to be significant for the long-run equation, columns (3) and (4)). In sum, the VIX appears to be a sensible measure of high frequency changes in risk appetite as hypothesized by the literature, although HY reflects market sentiment better over the long run.

\section{Robustness IV: Missing fundamentals}

In the previous tests, credit ratings were treated mainly as a control for country-specific fundamentals, focusing the analysis on the results associated with risk. In so doing, we abstracted from the influence of country fundamentals per se, beyond what is captured by the rating assigned to the country. There are at least two reasons why one would like to have a closer look at the role of actual fundamentals. The first one is the belief that ratings do not always reflect the macroeconomic context. More precisely, many observers have pointed out that ratings provide, at best, only a partial account of the actual

\footnotetext{
${ }^{8}$ The VIX, compiled by the Chicago Board Options Exchange (CBOE) measures the expected stock market volatility over the next 30 calendar days, from the prices of the S\&P 500 stock index options for a wide range of strike prices. The calculation is independent of any model and derives the expected volatility by averaging the weighted prices of out-of-the money puts and calls. Historically, in periods of financial stress accompanied by steep market declines, option prices - and VIX - tend to rise; the opposite happens when market sentiment improves.
} 
likelihood of default of individual countries. In fact, there is a growing belief that rating agencies tend to lag spreads in their reaction to significant news and, more generally, to reflect credit risk only imperfectly -hence the substantial dispersion of spreads within the same rating category. Table 7 illustrates the point: 12 months before recent default episodes, sovereign ratings assigned by the main rating agencies failed in many cases to sound the alarm. At any rate, to the extent that ratings are only a partial proxy for country-specific factors, it is essential for our purposes to test whether the incidence of global factors reported above is robust to a more parsimonious specification.

A second, related motivation is to evaluate the influence of ratings beyond and above the evolution of country-specific fundamentals. While their information content has been questioned on various grounds, the results reported above indicate that they exhibit a significant explanatory power for both the long-run level and the short-run variation of emerging spreads. Is this result indicating that they adequately capture relevant country information, or that they exert an influence of its own, not necessarily related to the evolution of the country's economy? In other words, could ratings be considered as an additional exogenous factor that influences the borrowing cost of emerging economies, independently of whether or not they reveal valuable information? ${ }^{9}$

These considerations presume that actual fundamentals may influence both the level of spreads and the way they comove with risk appetite beyond what is summarized by the credit rating. To verify this view, we add to our long-run specification dummies per country-year and country-month to capture the influence of fundamentals identified in the literature as determinants of sovereign risk, such as the country's leverage ratio, the degree of (financial and institutional) development, or cyclical output fluctuations, which are typically sampled at those frequencies.

Table 8 reports the results. The coefficients and explanatory power of the original baseline equation variables remain notably stable using monthly, weekly and even daily datasets, indicating that their influence is largely independent of country's fundamentals, although the power of the international rate is weakened by the inclusion of monthly dummies. While this is reassuring for the two exogenous

\footnotetext{
${ }^{9}$ If so, the influence of ratings on bond pricing could be regarded as an additional external source of volatility, bearing the question about the extent to which markets react to the relevant country-specific economic data. However, Mora (2004), in an updated assessment of this issue, emphasizes that the lagging nature of ratings may actually smooth out the impact of deteriorating fundamentals in the run up to a crisis.
} 
global factors, it is somewhat intriguing for the case of ratings that, in principle, are conceived as summary indicators of the relevant country-specific factors now included.

As noted, this may be due to the fact that, although investors generally recognize the limitations that ratings display in practice, the norms that inform their decisions force them to take credit ratings as an additional argument -suggesting that, to the extent that they reflect the evolution of the country's economy only partially, they may be regarded as a source of variability that is partially exogenous to the policy maker. However, there is another, simpler hypothesis that seems to match the evidence more closely: ratings are, in most cases, endogenous to spreads. Figure 4 illustrates this point graphically. Mimicking an event-study exercise, the first panel shows the residuals from a regression using the specification of column (6) in Table 8 without the ratings variable, averaged over a 40-day window centered on the grading event, where the latter coincides with positive and negative changes in the rating. As the figure clearly shows, downgrades are preceded by increases in spreads and, apart from a mild contemporaneous adjustment (of about 50 bps), exert no substantial impact. The opposite applies to downgrades, although in this case the preceding decline in spreads is smaller.

Does this evidence prove that ratings are endogenous to market reaction (in this case, spreads)? Not necessarily, since the market may be simply reacting in anticipation of regrading. Moreover, agencies themselves typically anticipate regradings by changing their own credit outlook -a reason to use the latter to refine the information contained in the rating. However, the second panel of the figure casts doubt on this possibility. There, we replicate the event-study exercise, this time defining as event a change in the credit outlook given by the rating agency. The logic is straightforward: if the rating does more than just validating the perceptions of the market, then changes in outlook (the way agencies have to signal the presence of new information that may merit a risk reassessment) should have an impact on asset prices. The results, however, are strikingly similar to those in the first panel. This is in line with the econometric test in Table 9, where our HY measure is adjusted to reflect changes in the credit outlook (the first two columns reproduce the previous results for ease of comparison). ${ }^{10}$ Ratings

\footnotetext{
10 The outlook could be thougth as a five-notch grading scale around the credit rating: positive, positive watch, neutral, negative watch, and negative. In the outlook-augmented ratings we give each notch a 0.2 value. Thus, if our rating variable takes the value 13 for a BBB bond, a BBB with negative watch outlook would take a value of 12.8 and one with negative outlook a value of 12.6
} 
improve slightly their explanatory power, but the new specification does not introduce any visible change in the remaining coefficients.

In sum, the presumption that ratings are a reasonable proxy for fundamental risk is questioned by the data. While their inclusion as control may still be justified (since they appear to exert a contemporaneous influences on spreads and, at any rate, their exogeneity should not biased the estimation of the remaining coefficients), attributing the (strong) link between ratings and spreads to the incidence of country-specific factors may be misleading, overstating the role of the latter -and understating the influence of global factors.

\section{Robustness V: Risk appetite or corporate risk?}

Going back to our reduced-form model, one natural question is to what extent the assumption of constant corporate risk influences the results and, more generally, whether the high yield spread is capturing changes in perceived risk together with changes in its price. In particular, how did an episode such as the Enron scandal, presumably associated with a reassessment of corporate default risk, affect the evolution of HY? The answer to these questions has important implications for the interpretation of the previous results, which hold only if $H Y$ does not reflect changes in global corporate risk.

A casual look at the evidence help dispel these concerns. Figure 5 shows the evolution of the weighted average rating of the corporate bond sample based on which the high yield spread is computed $(\operatorname{rating}(H Y))$. As can be seen, this rating moves within a very limited range of less than half-notch, hardly a significant source of variability. Moreover, increases in $H Y$ in the latest period, while negatively correlated with the rating (as expected), do not appear to reflect a visible deterioration of the risk (as perceived by the rating agencies). ${ }^{11}$ On the contrary, the Enron crisis coincides with a downward revision of corporate risk, as reflected by the improvement of corporate ratings (as a result, the correlation between the two turns positive during the period).

The implication of these findings (namely, that $H Y$ captures the price rather than the quantity of risk) is confirmed by the regressions in Table 10, where we include the corporate rating measure directly in

\footnotetext{
${ }^{11}$ Nor do they reflect increases in the incidence of U.S. corporate bankruptcies, which actually declined steadily in the period under study.
} 
the regression. As expected, the new control is not significant and has no effect on the rest of the coefficients. The same message is given by the last two columns. There, we replaced the HY index by the BBB spread, which should be less sensitive to risk (lower than the one associated with the index) and risk changes, and a better gauge of changes in the price of risk. Reassuringly, the new measure underperforms the HY index. ${ }^{12}$

\section{Predictions}

One way to gauge how much of the variation in emerging market spread can be explained by the few exogenous variables identified in our baseline model consists in simulating the path of individual spreads based solely on the long-run specification. We perform this test by calibrating this equation using data through end-2001, and simulating the behavior of spreads for the remaining period (January 2002- November 2005). ${ }^{13}$ Specifically, in order to assess the relative predictive power of global factors, we re-estimate the long-run specification of Table 8, column (1), and compute the out-of-sample path that results from variations in the global variables HY and the international rate, keeping ratings fixed at their end-2001 levels.

Figure 6 reports the results. ${ }^{14}$ It compares the actual EMBI spread with the predictions from the longrun equation. Three aspects deserve to be stressed in the figures. First, predictions are generally quite good, including for many Latin American countries that underwent severe episodes of capital account reversals in the period considered. Second, the predictions highlight the explanatory power of the two exogenous variables: despite short-term, transitory swings due to country-specific episodes, spread movements closely reflect these three variables, and eventually converge to levels that are largely explained by them. Third, although many of these episodes may have coincided with (and possibly facilitated by) a deterioration in those global factors, they far exceed the variability of the latter, suggesting that some country-specific ingredient was crucially in place at the time. Brazil is a case in

\footnotetext{
12 The same result is obtained when we proxy the price of risk by the spread on U.S. Baa bonds, which according to some authors is the best proxy for risk aversion (Blanchard, 2004).

13 As a result, some countries that were included in the EMBI after (or shortly before) 2001 are dropped due to lack of observations.

14 Naturally, one could readily obtain much more precise one-period-ahead forecasts by estimating the short run equation and adding it to the long-run one, i.e., computing $\mathrm{E}\left(\ln (\mathrm{embi})_{t}\right)=\mathrm{E}\left(\ln \left(\mathrm{embi} \mathrm{i}_{\text {long, }-1}\right)+\mathrm{E}(\Delta \ln (\mathrm{embi}))\right.$. Since our interest is in the persistent effect of global factors, the results are ommitted here (they are available from the authors on request).
} 
point: the financial turmoil of late 2002 associated with the uncertainty surrounding the election and the transition to a new government which was clearly independent of the evolution of global factors; once over, spreads rapidly converged to their long-run levels.

An even more starkly example of the incidence of long-run factors is provided by Argentina. Figure 7 shows the evolution of the spread before and after de sovereign default, and the predicted value for the post-default period, setting the rating at its levels as of end-2000. As can be seen, the prediction yields a spread of about 500 right after the exchange was concluded -very close to the one actually realized. Thus, using a model calibrated based on the information available before the crisis, the dramatic decline in spreads experienced by the country after the sovereign default was left behind could have been predicted simply as a result of the increase in risk appetite and the decline in international interest rates that followed.

\section{Final remarks}

Our tests attempted to estimate the variability explained by global factors, but adopted an agnostic approach to country-specific factors, which pose non-trivial empirical problems. Most available country-specific controls are sampled at too low a frequency and, even when they are available on a daily basis like credit ratings, are likely to be endogenous. Therefore, an accurate decomposition of emerging market spreads volatility into their systemic and idiosyncratic determinants is an uphill and still pending task.

This does not detract from the validity of our main result: Global factors, such as global liquidity and market sentiment, explain a large part of the (substantial) volatility of emerging market spreads -a connection that, while not new, has tended to strengthen over the years. The implications of these findings are immediate. On the one hand, no forecast of the borrowing cost (and, as a result, the fiscal sustainability) of emerging economies can ignore these exogenous factors (which, in addition, are often easier to predict than fundamentals). On the other, besides improving macro fundamentals, emerging economies need to take into account their exposure to global factors, and to devise mechanisms to reduce it. Financial integration brings contagion not only from other emerging economies but also 
from the rest of the developed world. In the absence of a concerted effort to reduce their effects, newcomers, like infants, had better take their shot well in advance. 
Table 1. Summary statistics

(monthly sample)

\begin{tabular}{lccccccc}
\hline Variable & Frequency & $\mathrm{N}$ & mean & median & Std Dev & min & max \\
\hline embi & Monthly & 3309 & 648.1935 & 402.7520 & 831.5839 & 7.0240 & 7078 \\
HY & Monthly & 191 & 580.8115 & 523 & 203.5349 & 307 & 1080 \\
rating & Monthly & 4351 & 10.8322 & 11 & 3.3172 & 1 & 18 \\
10YT & Monthly & 191 & 5.9228 & 5.86 & 1.3511 & 3.37 & 9.04 \\
VIX & Monthly & 191 & 19.4612 & 18.88 & 6.3882 & 10.63 & 44.28 \\
rating+outlook & Monthly & 4283 & 10.8453 & 11 & 3.3537 & 1 & 18 \\
Rating(HY) & Monthly & 131 & 4.4352 & 4.3925 & 0.1323 & 4.2347 & 4.7403 \\
HY(Split BBB) & Monthly & 131 & 250.8441 & 224.88 & 103.8955 & 114.25 & 563 \\
\hline
\end{tabular}

(weekly sample)

\begin{tabular}{lccccccc}
\hline Variable & Frequency & $\mathrm{N}$ & mean & median & Std Dev & $\min$ & $\max$ \\
\hline embi & Weekly & 14370 & 645.7757 & 399 & 832.7009 & -6 & 7222 \\
HY & Weekly & 493 & 583.6755 & 556 & 211.4735 & 301 & 1116 \\
rating & Weekly & 18919 & 10.8375 & 11 & 3.3125 & 1 & 18 \\
$10 Y$ T & Weekly & 834 & 5.9284 & 5.88 & 1.3443 & 3.18 & 9.07 \\
VIX & Weekly & 836 & 19.4045 & 18.36 & 6.4250 & 9.48 & 45.74 \\
rating+outlook & Weekly & 18620 & 10.8489 & 11 & 3.3506 & 1 & 18 \\
\hline
\end{tabular}


Table 2. Panel Unit Root Tests

\begin{tabular}{|c|c|c|c|c|}
\hline \multirow[t]{2}{*}{ Monthly panel } & \multicolumn{2}{|c|}{ Maddala-Wu } & \multicolumn{2}{|c|}{ Choi } \\
\hline & PMW & $\mathrm{p}$-Value & $\mathrm{Z}_{\mathrm{MW}}$ & $\mathrm{p}$-Value \\
\hline embi & 64.354 & 0.603 & 0.231 & 0.591 \\
\hline HY & 55.121 & 0.904 & -0.234 & 0.407 \\
\hline $10 \mathrm{YT}^{\prime}$ & 68.536 & 0.527 & -0.111 & 0.455 \\
\hline rating & 68.710 & 0.206 & 1.202 & 0.885 \\
\hline $\mathrm{EC}_{\mathrm{i}, \mathrm{t}-1}$ & 1308.99 & 0.000 & -7.992 & 0.000 \\
\hline \multirow[t]{2}{*}{ Weekly panel } & \multicolumn{2}{|c|}{ Maddala-Wu } & \multicolumn{2}{|c|}{ Choi } \\
\hline & PMW & $\mathrm{p}$-value & $\mathrm{Z}_{\mathrm{MW}}$ & $\mathrm{p}$-value \\
\hline embi & 59.691 & 0.754 & 0.163 & 0.435 \\
\hline HY & 36.816 & 0.999 & -0.289 & 0.389 \\
\hline $10 \mathrm{YT}^{\mathrm{T}}$ & 51.306 & 0.955 & -0.099 & 0.480 \\
\hline rating & 47.648 & 0.876 & -2.396 & 0.992 \\
\hline $\mathrm{EC}_{\mathrm{i} ; \mathrm{t}-1}$ & 4310.77 & 0.000 & -8.905 & 0.000 \\
\hline
\end{tabular}

Note: $\mathrm{EC}_{\mathrm{i}, \mathrm{t}-1}$ are the residuals of the long run equilibrium relationship presented in column (1) ((4)) of Table 3 for monthly data (weekly data). All variables are in logs. Lags for the panel unit root tests were selected using Schwarz information criterion. 
Table 3. Global factors and emerging market spreads

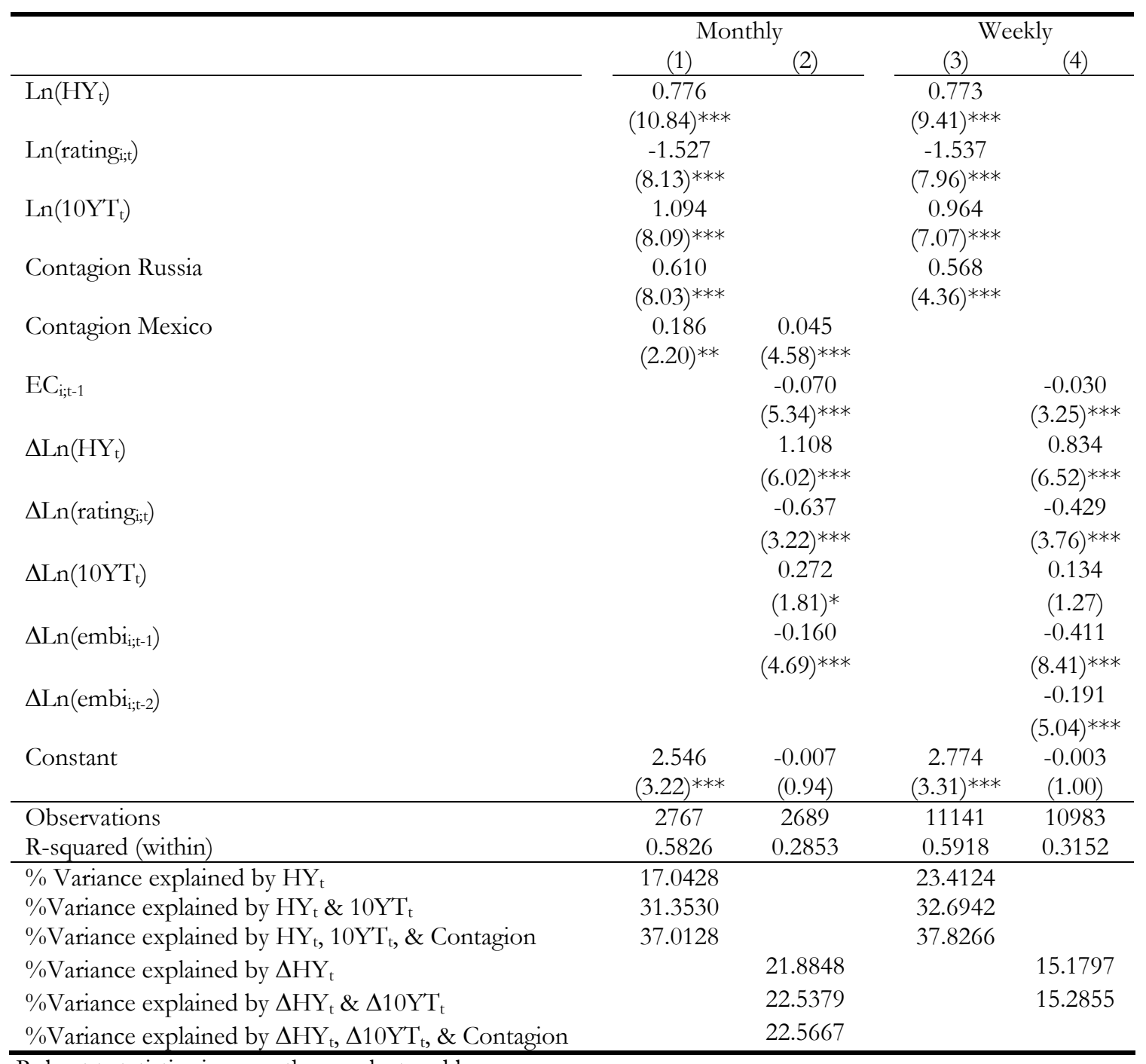

Robust $\mathrm{t}$ statistics in parentheses, clustered by year

* significant at $10 \%$; ** significant at $5 \%$; *** significant at $1 \%$ 


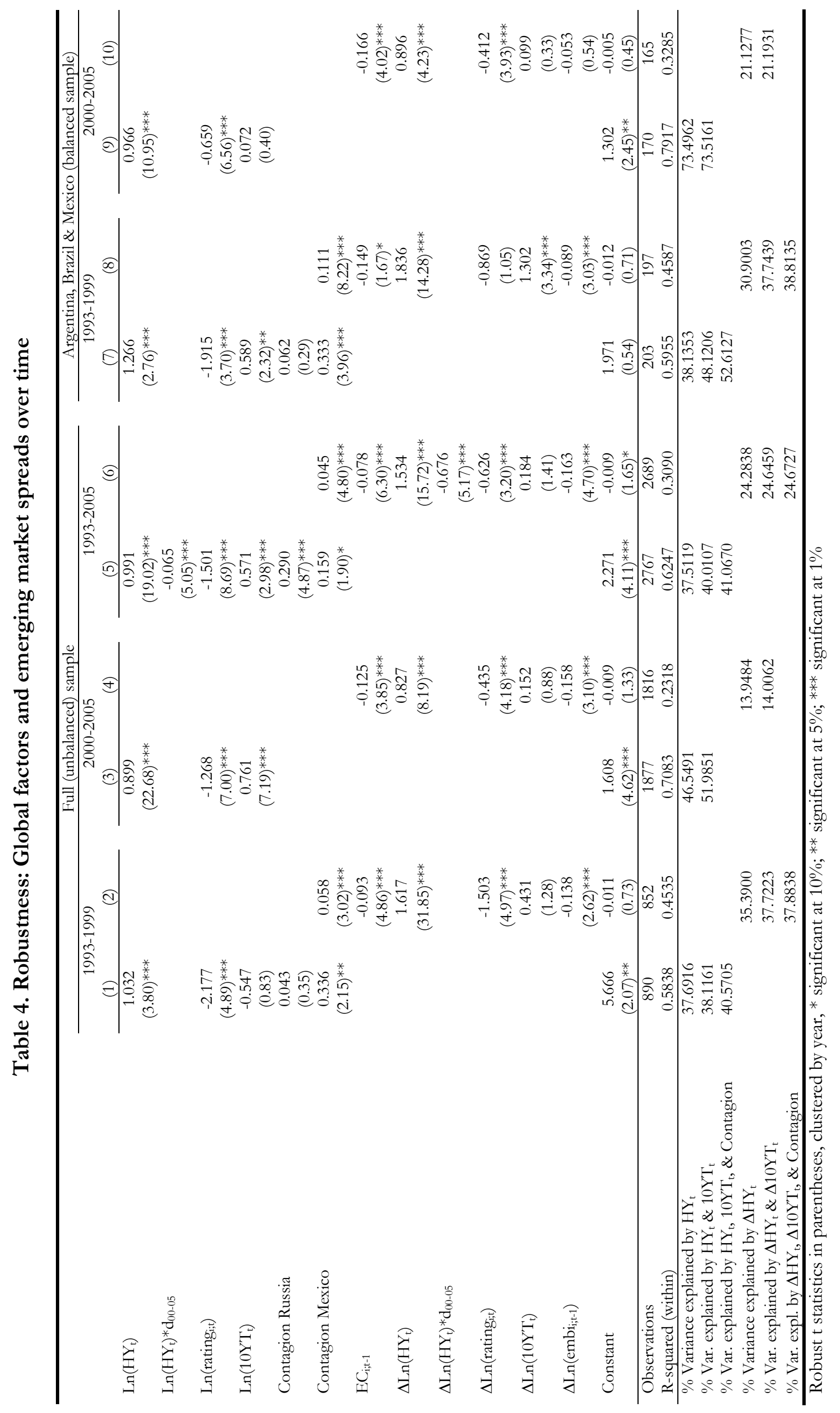


Table 5. Robustness: Asymmetries

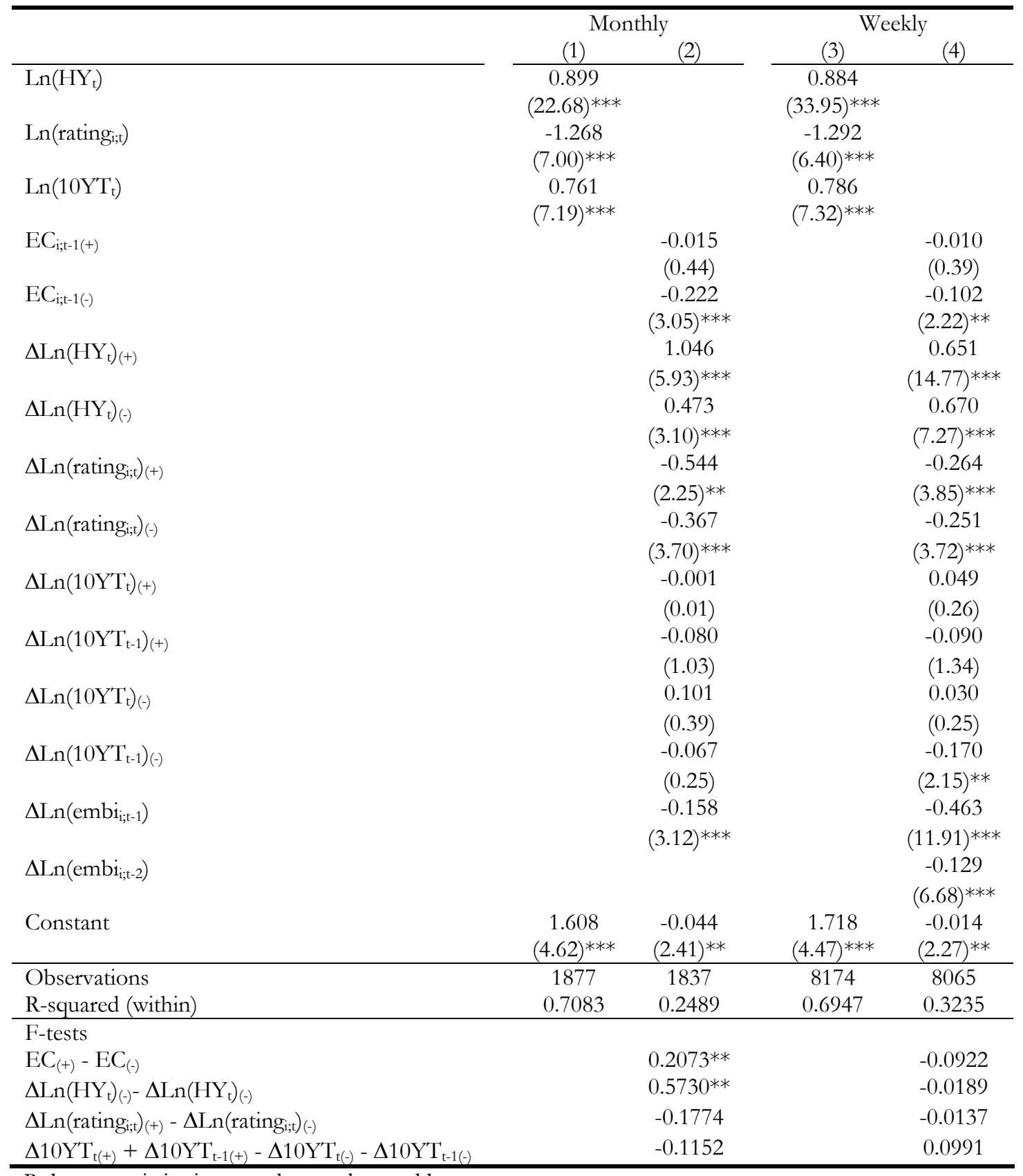

Robust t statistics in parentheses, clustered by year

* significant at $10 \%$; ** significant at 5\%; *** significant at $1 \%$ 


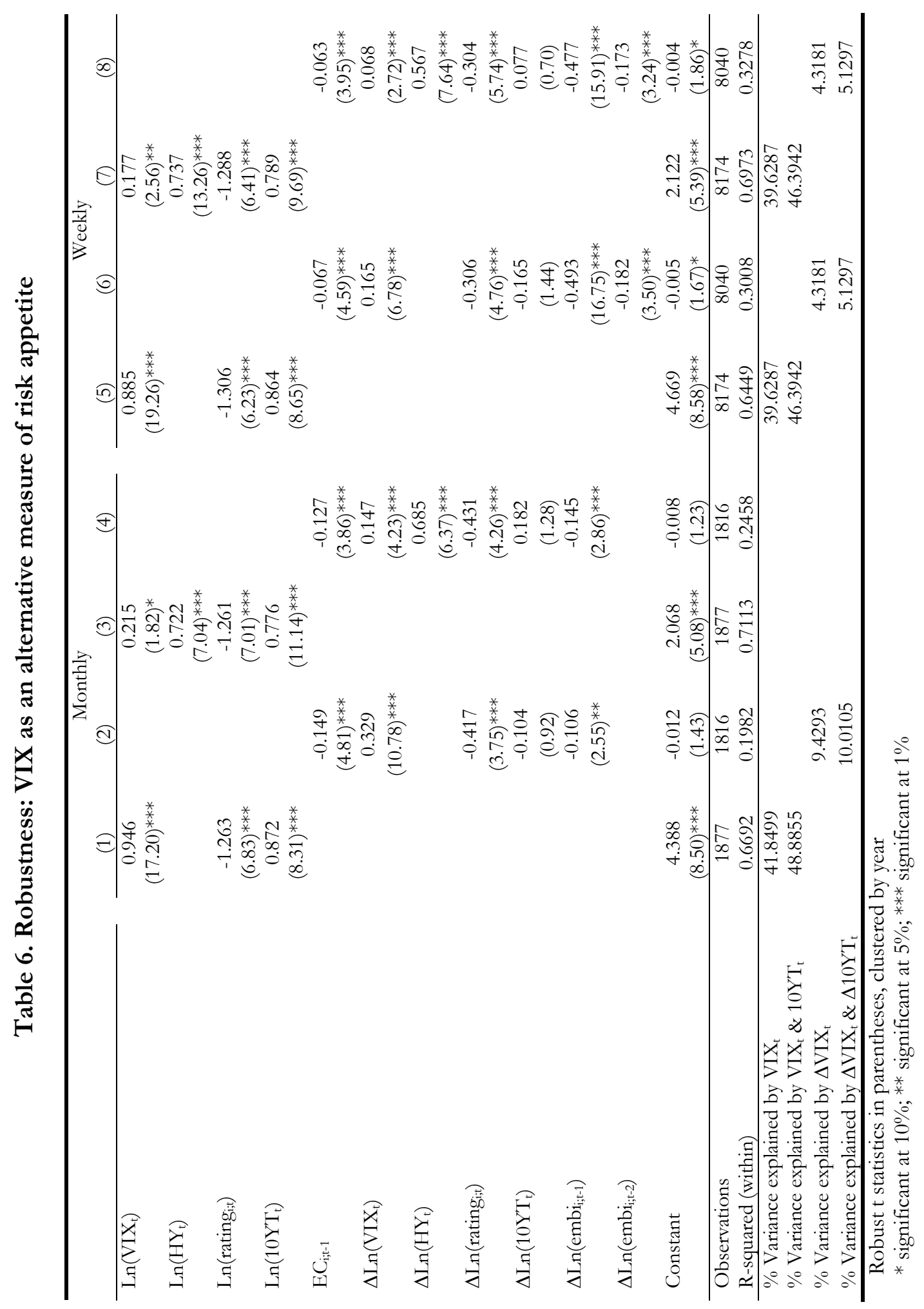


Table 7. Robustness: Sovereign credit ratings 12 months before default

\begin{tabular}{|c|c|c|c|c|c|}
\hline Country & Month of default & \multicolumn{2}{|c|}{ S\&P } & \multicolumn{2}{|c|}{ Moody's } \\
\hline Dominican Republic & February 2005 & CC & 2 & B3 & 6 \\
\hline Venezuela & January 2005 & B- & 6 & Caa1 & 5 \\
\hline Uruguay & May 2003 & BB- & 9 & $\mathrm{Ba} 2$ & 10 \\
\hline Indonesia & April 2002 & B- & 6 & B3 & 6 \\
\hline Argentina & November 2001 & BB- & 9 & B1 & 8 \\
\hline Ukraine & January 2000 & $\mathrm{n} / \mathrm{a}$ & $\mathrm{n} / \mathrm{a}$ & B3 & 6 \\
\hline Indonesia & April 2000 & $\mathrm{CCC}+$ & 5 & B3 & 6 \\
\hline Ecuador & July 2000 & $\mathrm{n} / \mathrm{a}$ & $\mathrm{n} / \mathrm{a}$ & B3 & 6 \\
\hline Pakistan & January 1999 & $\mathrm{~B}+$ & 8 & $\mathrm{~B} 2$ & 7 \\
\hline Russian Federation & January 1999 & BB- & 9 & $\mathrm{Ba} 2$ & 10 \\
\hline
\end{tabular}

Source: Authors' calculations based on S\&P and Moody's data.

Foreign currency rating of long-term debt. 1=Default, 13=high grade. 


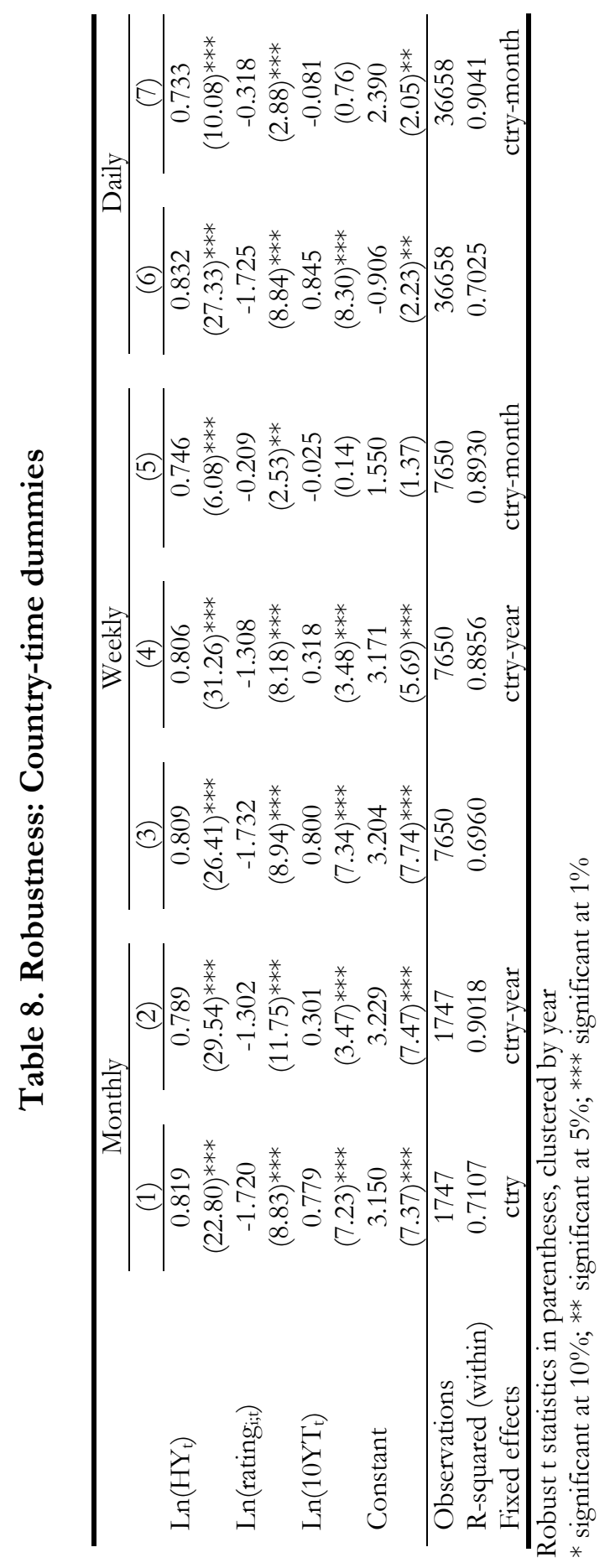




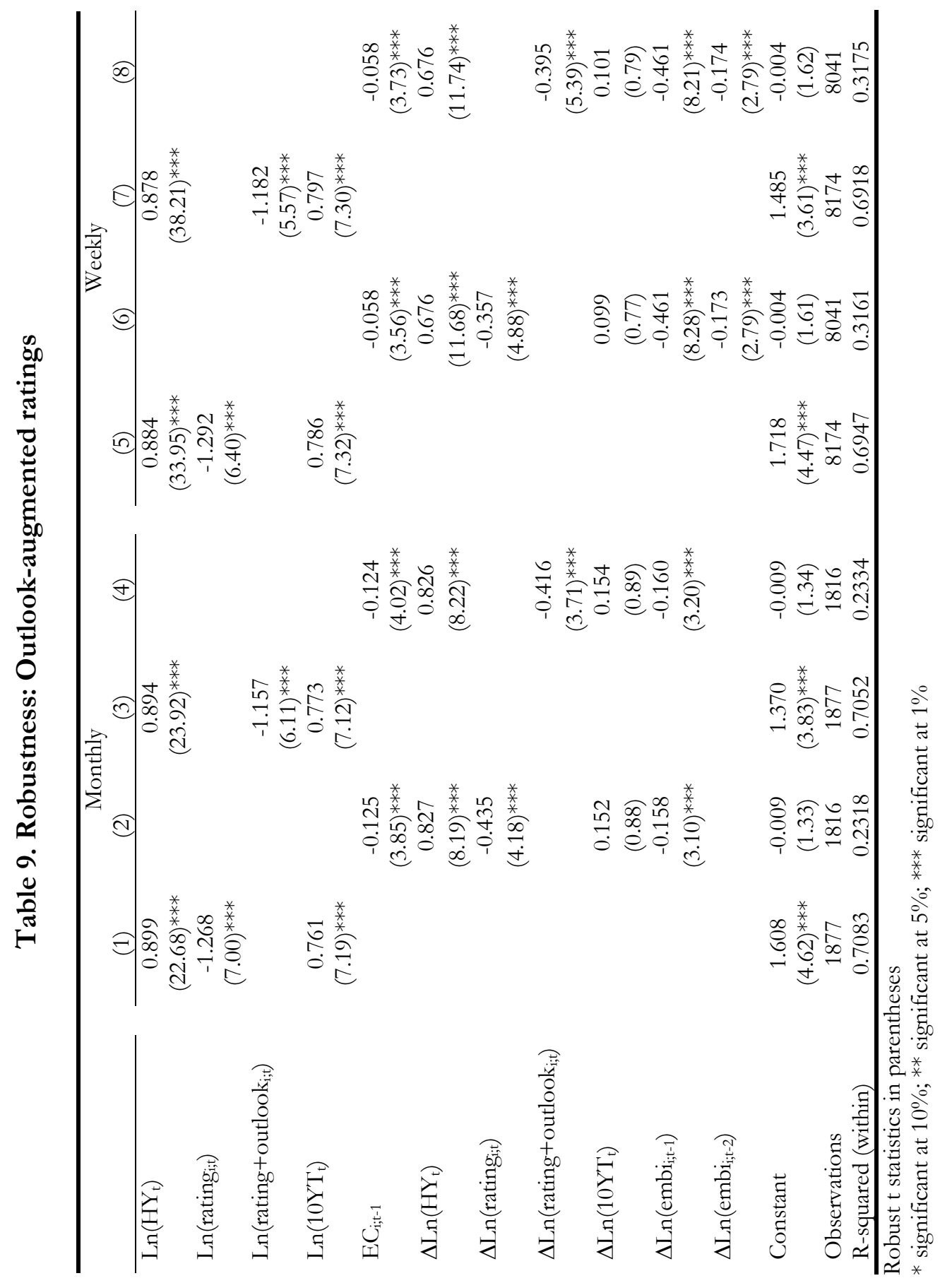


Table 10. Robustness: BBB spread (monthly)

\begin{tabular}{|c|c|c|c|c|}
\hline & $(1)$ & (2) & (3) & (4) \\
\hline $\operatorname{Ln}\left(\mathrm{HY}_{\mathrm{t}}\right)$ & $\begin{array}{c}0.849 \\
(25.54)^{* * *}\end{array}$ & & & \\
\hline $\mathrm{Ln}\left(\mathrm{HY}\right.$ splitBBB $\left.{ }_{\mathrm{t}}\right)$ & & & $\begin{array}{c}0.789 \\
(18.49)^{* * *}\end{array}$ & \\
\hline $\operatorname{Ln}\left(\operatorname{Rating}\left(\mathrm{HY}_{\mathrm{t}}\right)\right)$ & $\begin{array}{c}-0.577 \\
(0.72)\end{array}$ & & $\begin{array}{c}-1.011 \\
(0.59)\end{array}$ & \\
\hline $\operatorname{Ln}\left(\right.$ Rating $\left._{\mathrm{i}, \mathrm{t}}\right)$ & $\begin{array}{c}-1.705 \\
(8.83)^{* * *}\end{array}$ & & $\begin{array}{c}-1.731 \\
(9.10)^{* * *}\end{array}$ & \\
\hline $\operatorname{Ln}\left(10 \mathrm{YT}_{\mathrm{t}}\right)$ & $\begin{array}{c}0.764 \\
(7.08)^{* * *}\end{array}$ & & $\begin{array}{c}0.891 \\
(10.01)^{* * *}\end{array}$ & \\
\hline $\mathrm{EC}_{\mathrm{i}, \mathrm{t}-1}$ & & $\begin{array}{c}-0.137 \\
(3.56)^{* * *}\end{array}$ & & $\begin{array}{c}-0.130 \\
(3.89)^{* * *}\end{array}$ \\
\hline$\Delta \operatorname{Ln}\left(\mathrm{HY}_{\mathrm{t}}\right)$ & & $\begin{array}{c}0.759 \\
(6.11)^{* * *}\end{array}$ & & \\
\hline$\Delta \mathrm{Ln}(\mathrm{HY}$ splitBBB $\mathrm{t})$ & & & & $\begin{array}{c}0.517 \\
(5.92)^{* * *}\end{array}$ \\
\hline$\Delta \operatorname{Ln}\left(\operatorname{Rating}\left(\mathrm{HY}_{\mathrm{t}}\right)\right)$ & & $\begin{array}{c}2.151 \\
(2.81)^{* * *}\end{array}$ & & \\
\hline$\Delta \operatorname{Ln}\left(\right.$ Rating $\left._{\mathrm{i}, \mathrm{t}}\right)$ & & $\begin{array}{c}-0.843 \\
(5.26)^{* * *}\end{array}$ & & $\begin{array}{c}-0.793 \\
(5.79)^{* * *}\end{array}$ \\
\hline$\Delta \operatorname{Ln}\left(10 \mathrm{YT}_{\mathrm{t}}\right)$ & & $\begin{array}{l}0.161 \\
(0.83)\end{array}$ & & $\begin{array}{c}-0.022 \\
(0.12)\end{array}$ \\
\hline$\Delta \mathrm{Ln}\left(\right.$ Spread $\left._{\mathrm{i}, \mathrm{t}-1}\right)$ & & $\begin{array}{c}-0.152 \\
(2.95)^{* * *}\end{array}$ & & $\begin{array}{c}-0.123 \\
(3.26)^{* * *}\end{array}$ \\
\hline Constant & $\begin{array}{c}3.799 \\
(3.20)^{* * *}\end{array}$ & $\begin{array}{r}-0.011 \\
(1.64)\end{array}$ & $\begin{array}{c}5.321 \\
(2.27)^{* *}\end{array}$ & $\begin{array}{c}-0.015 \\
(1.97)^{* *}\end{array}$ \\
\hline Observations & 1805 & 1755 & 1805 & 1784 \\
\hline R-squared (within) & 0.7183 & 0.2427 & 0.7019 & 0.2079 \\
\hline
\end{tabular}


Figure 1. HY index and Embi

Mean normalized values $($ mean $=100)$
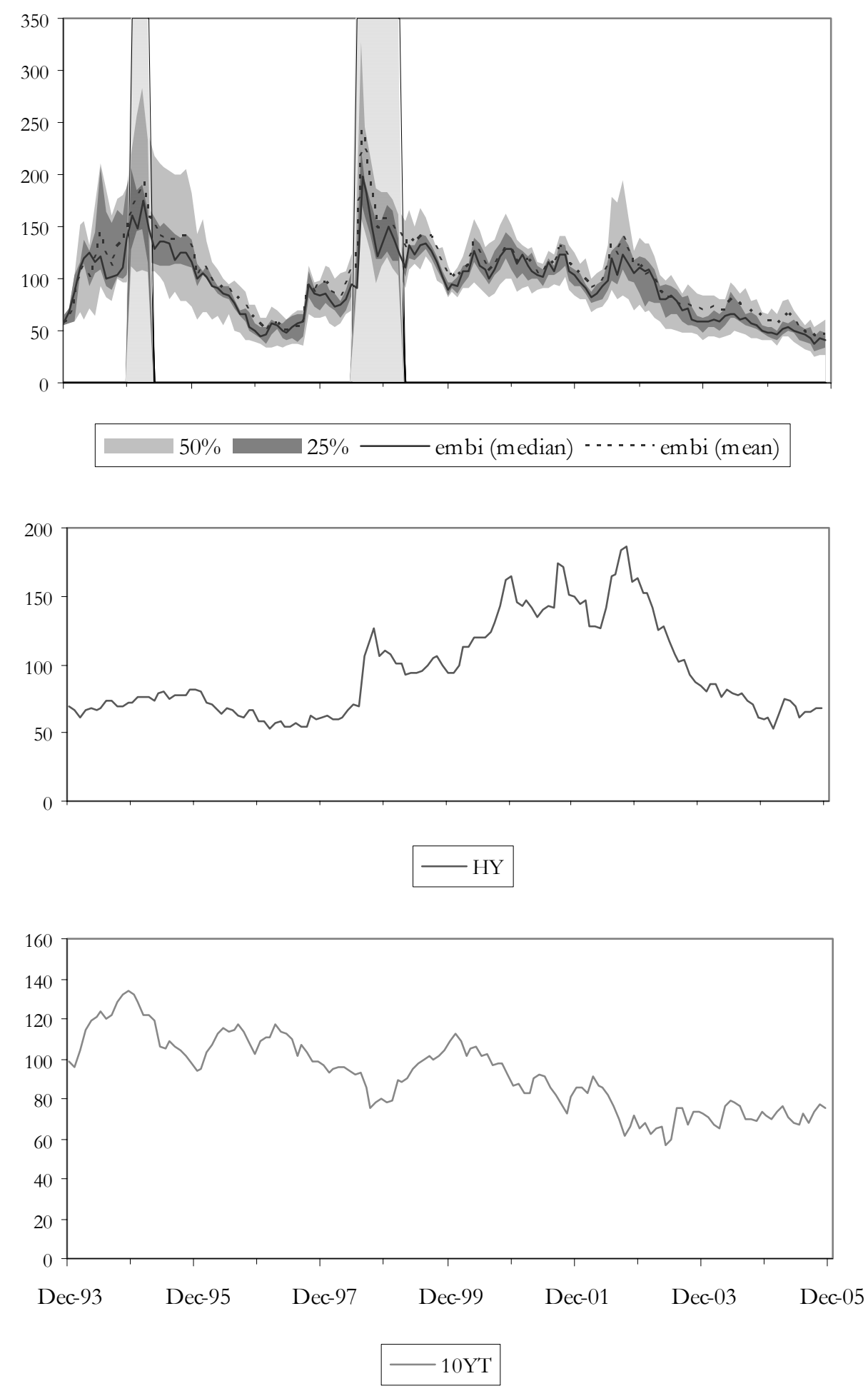
Figure 2. Robustness I: Structural break

(based on column (1) of Table 3)

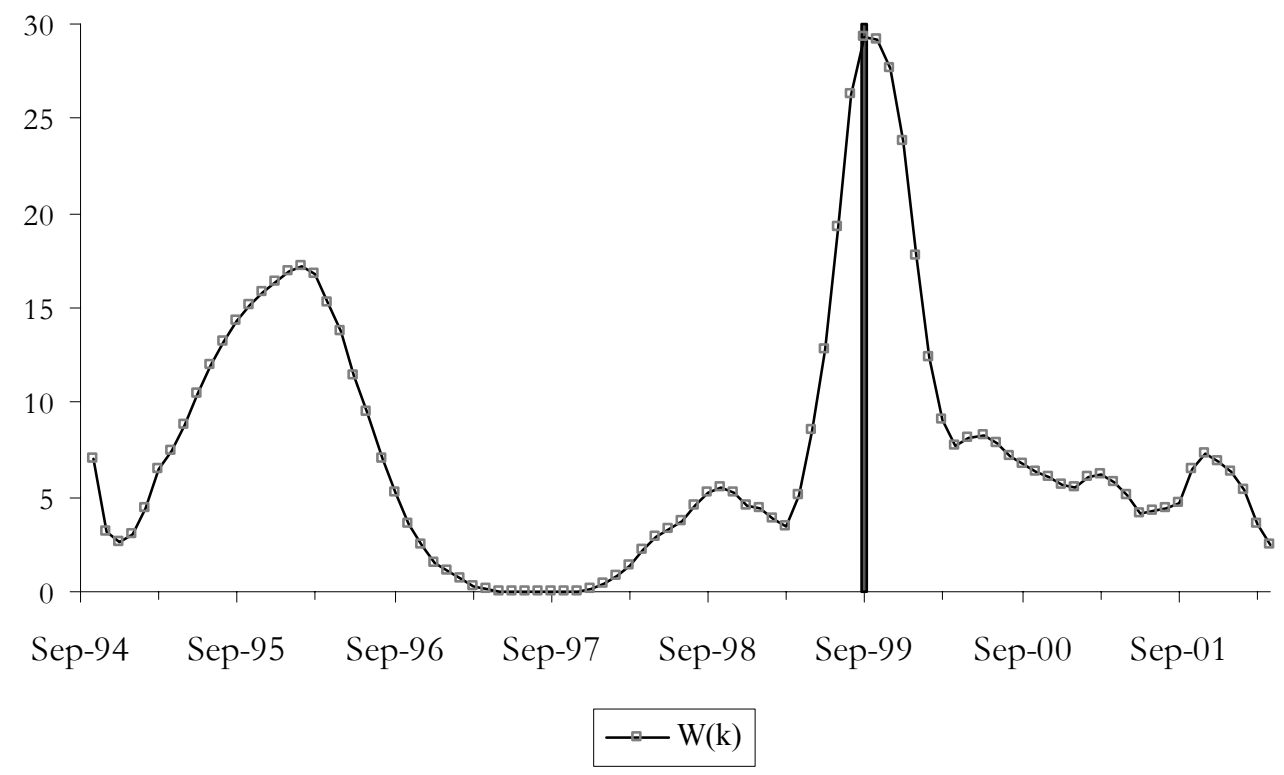


Figure 3. Robustness III: HY index and VIX

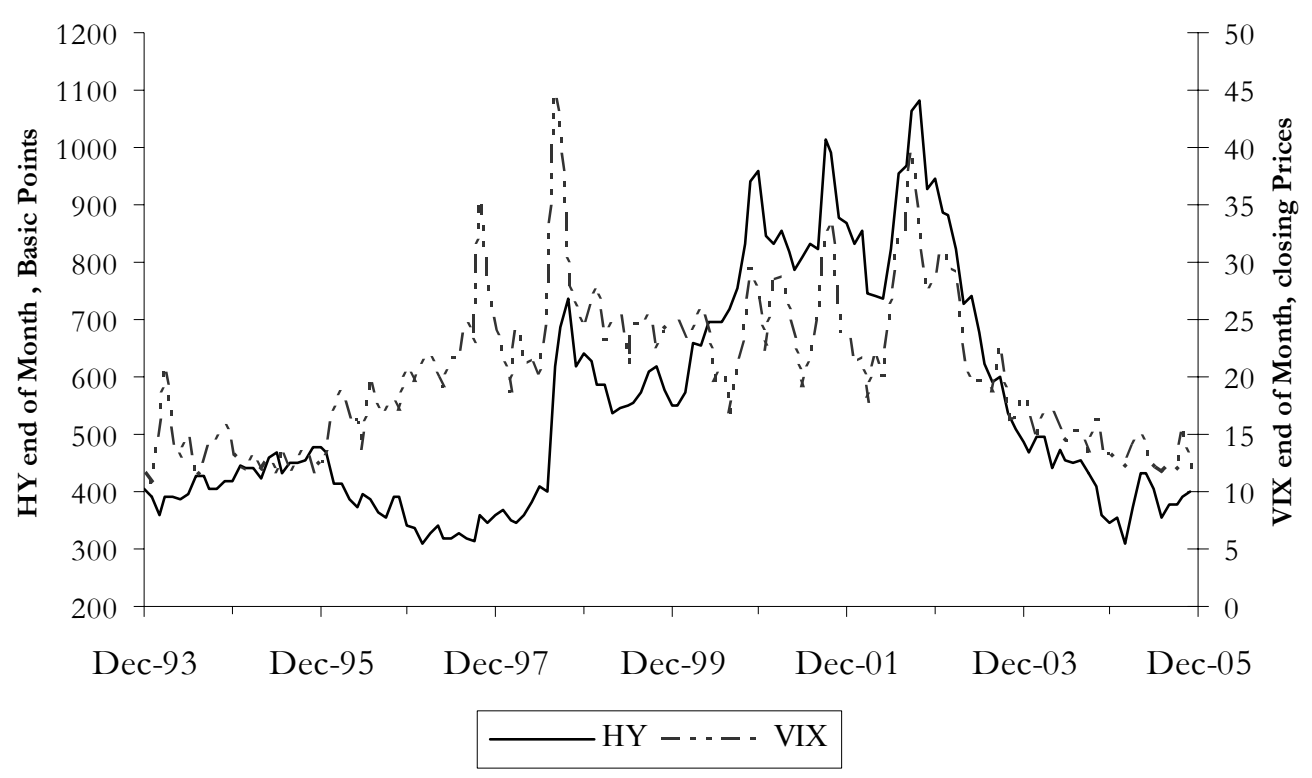


Figure 4. Robustness IV, events study: rating and outlook changes.

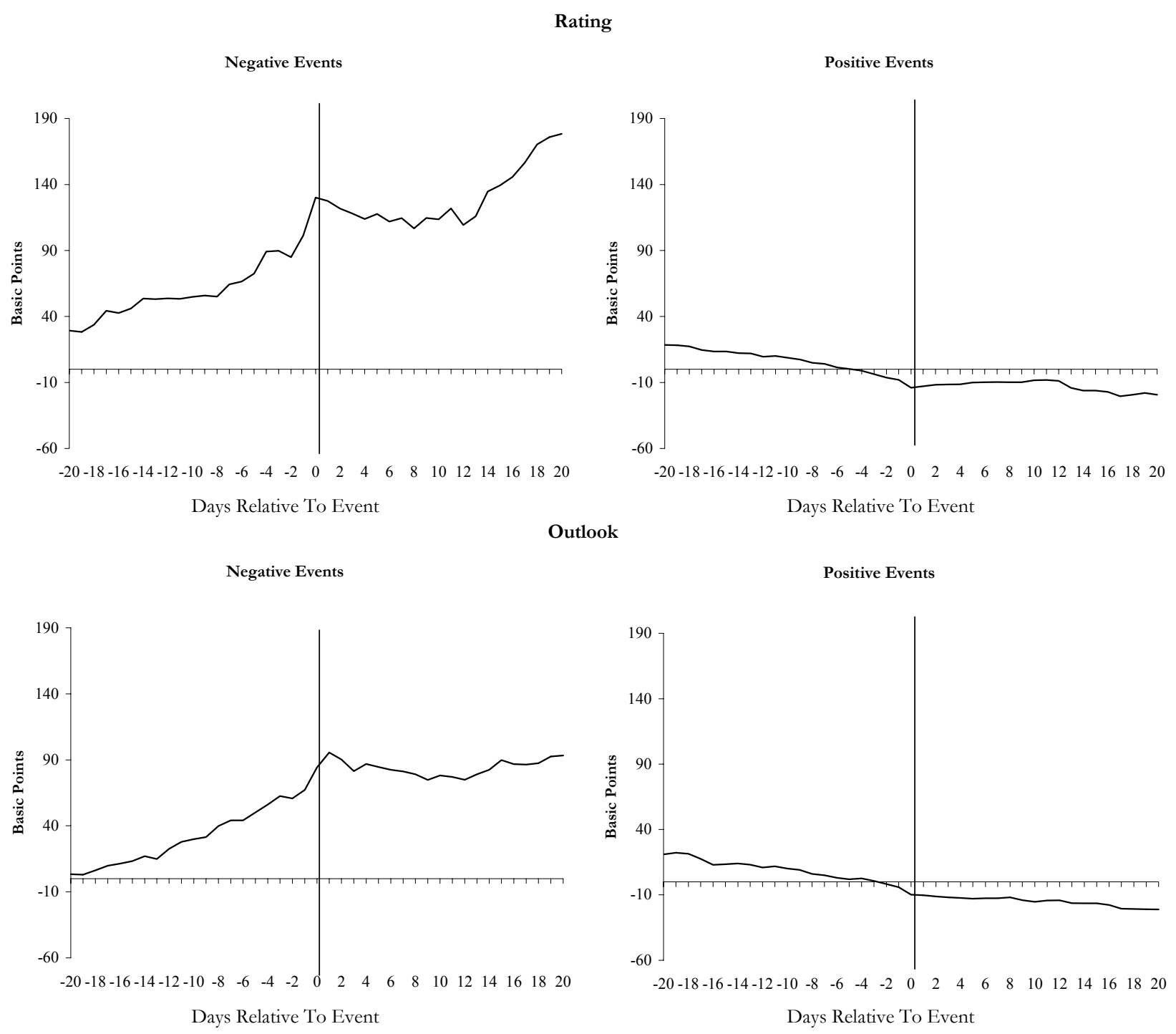


Figure 5. Robustness V: HY yields and HY ratings

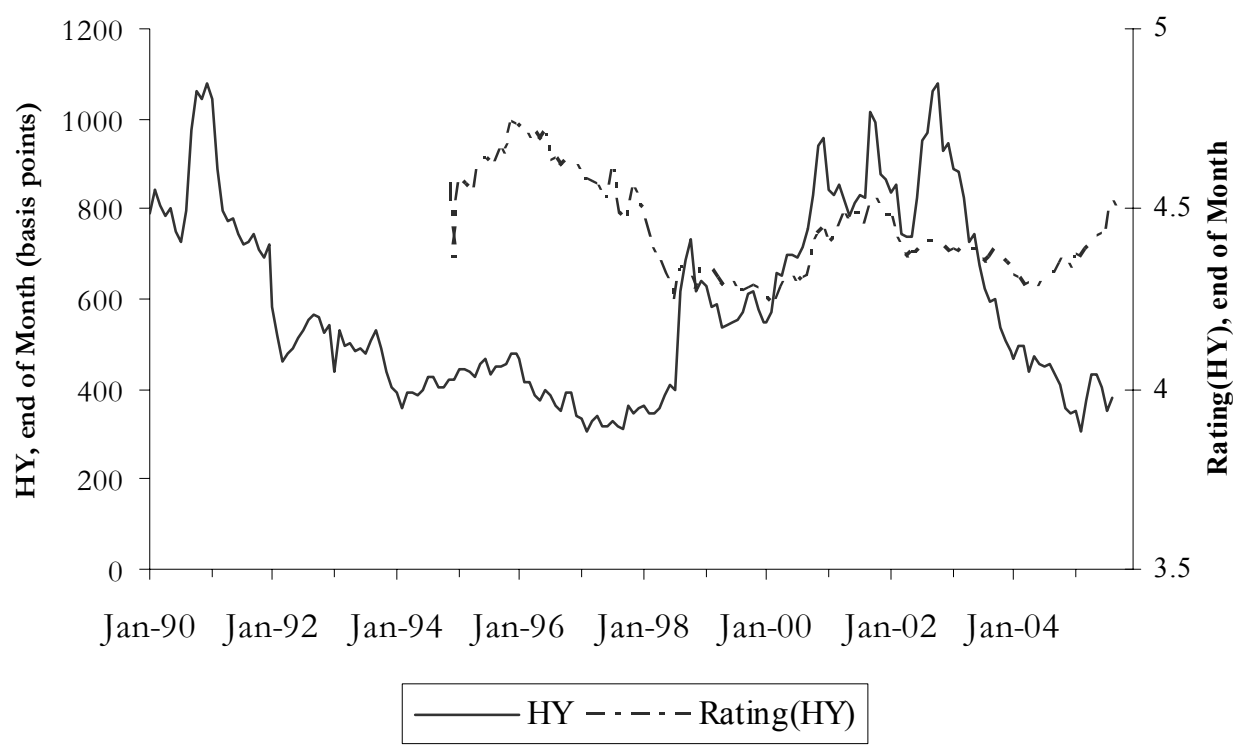




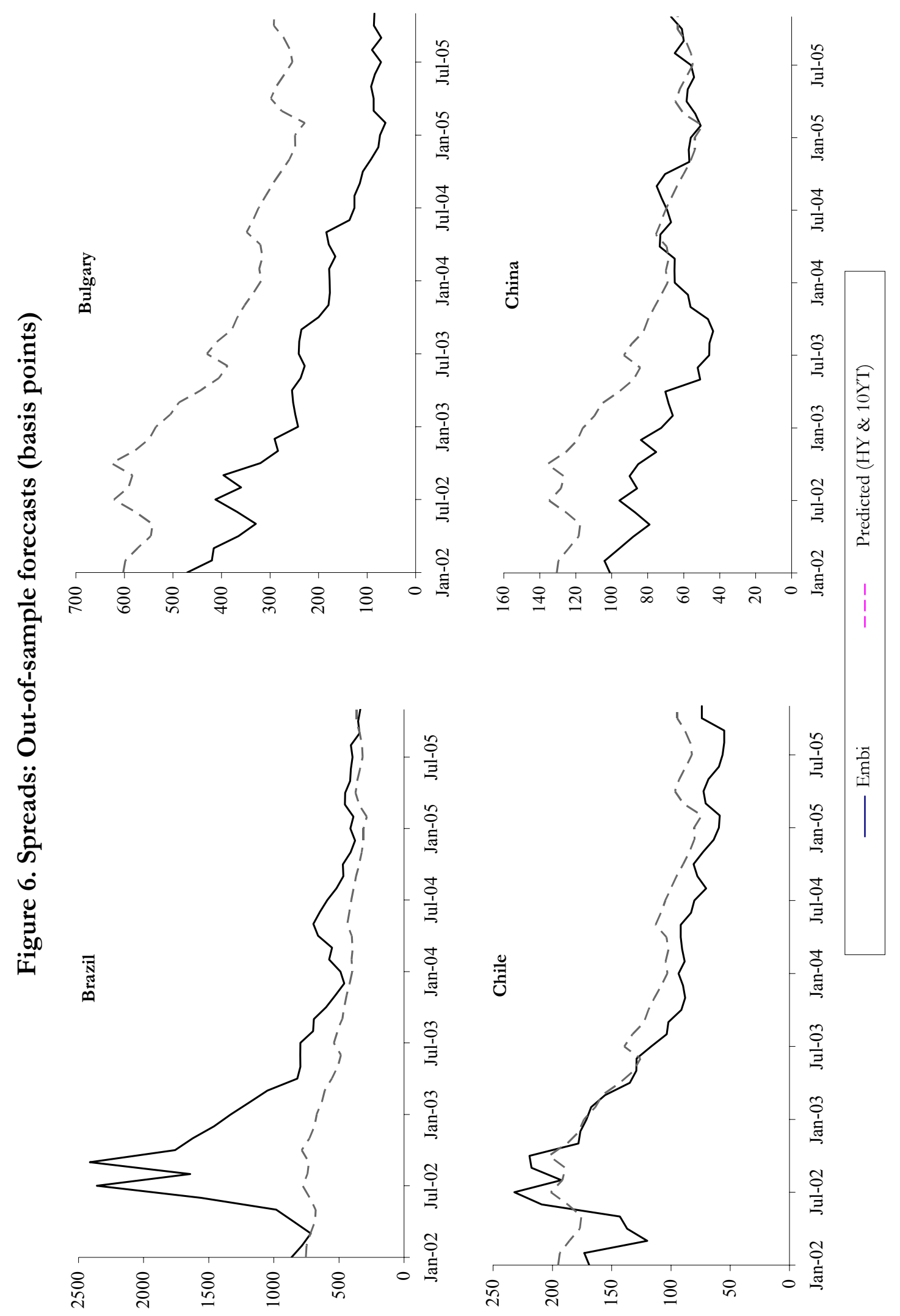




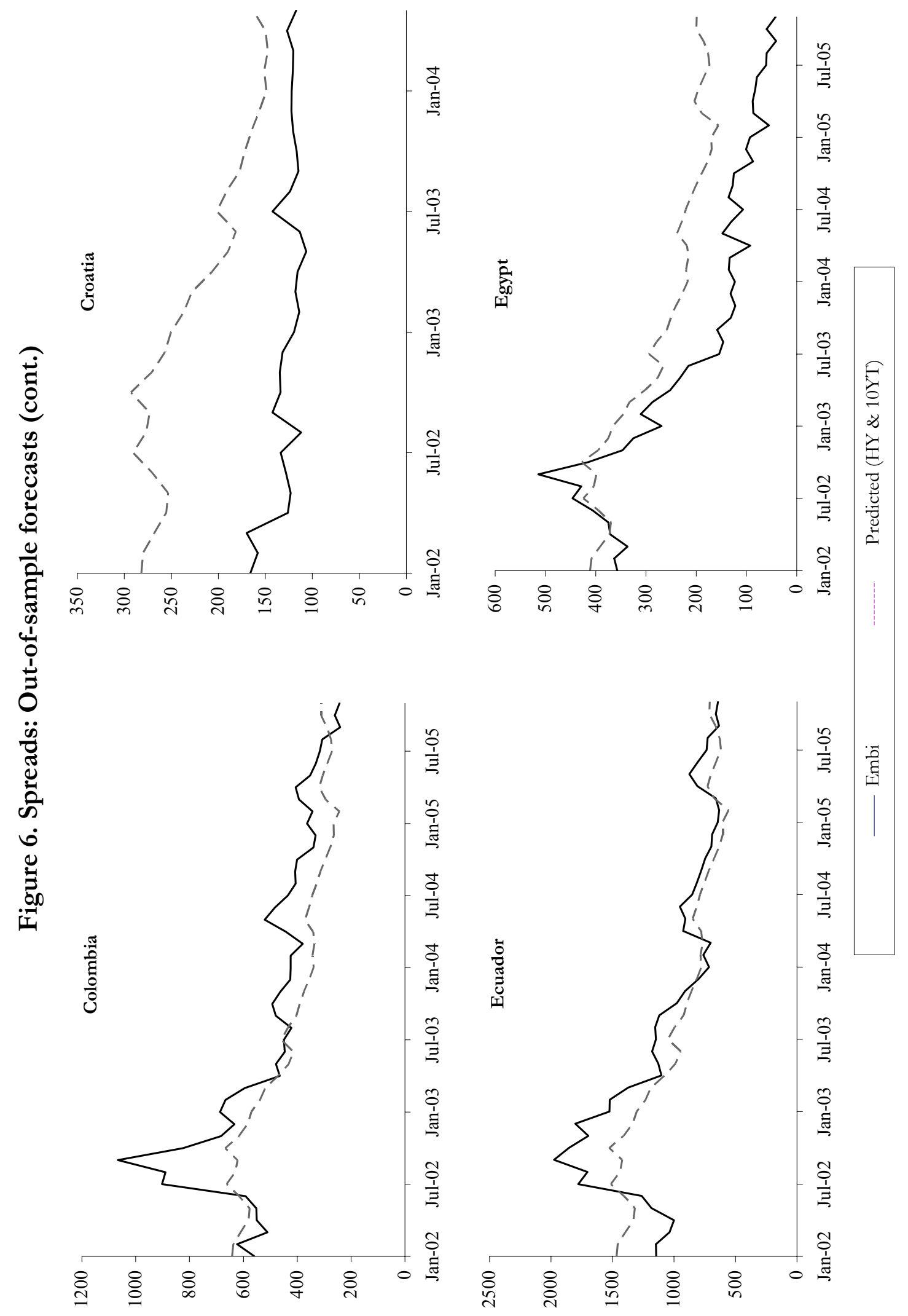




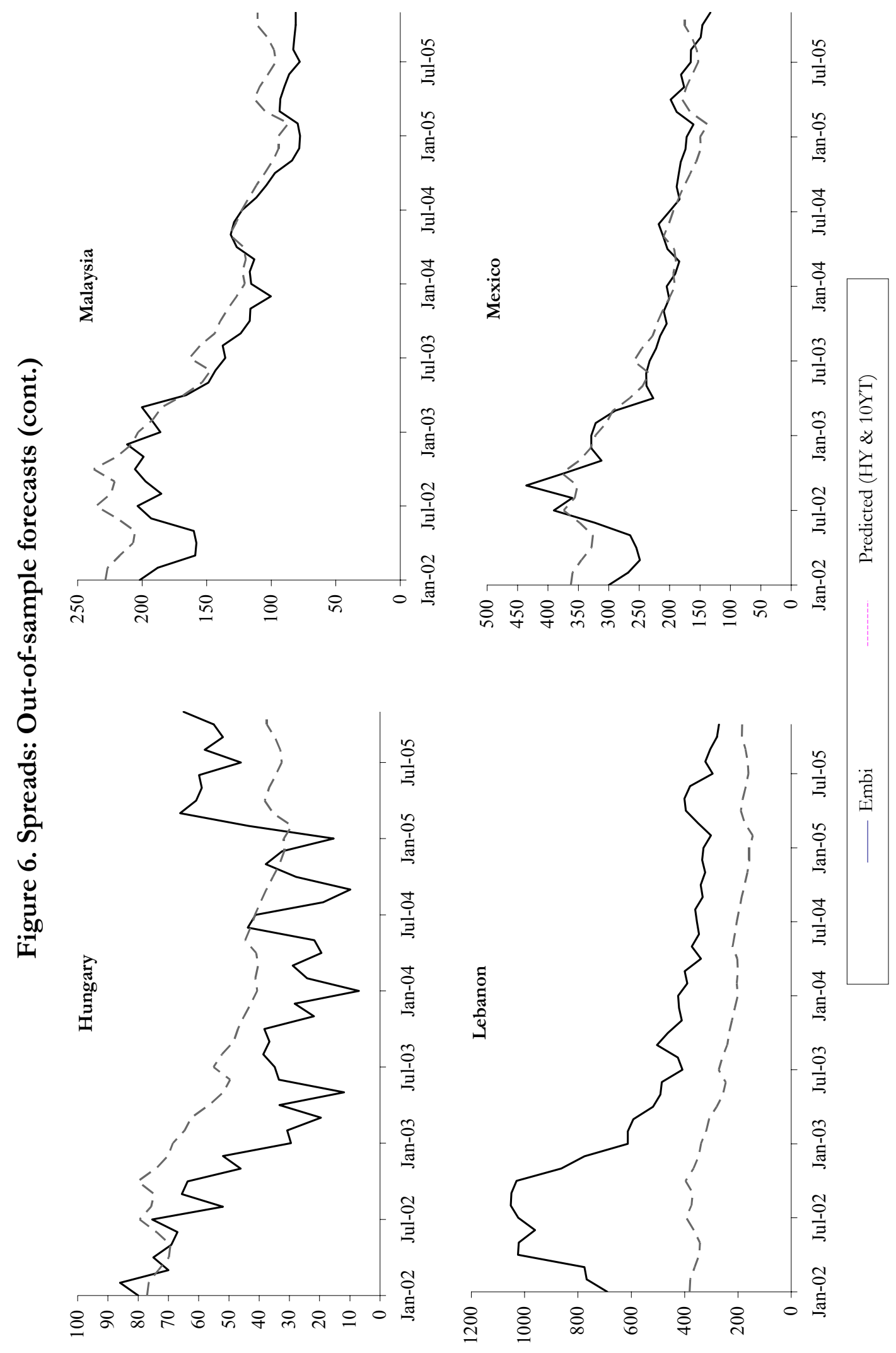




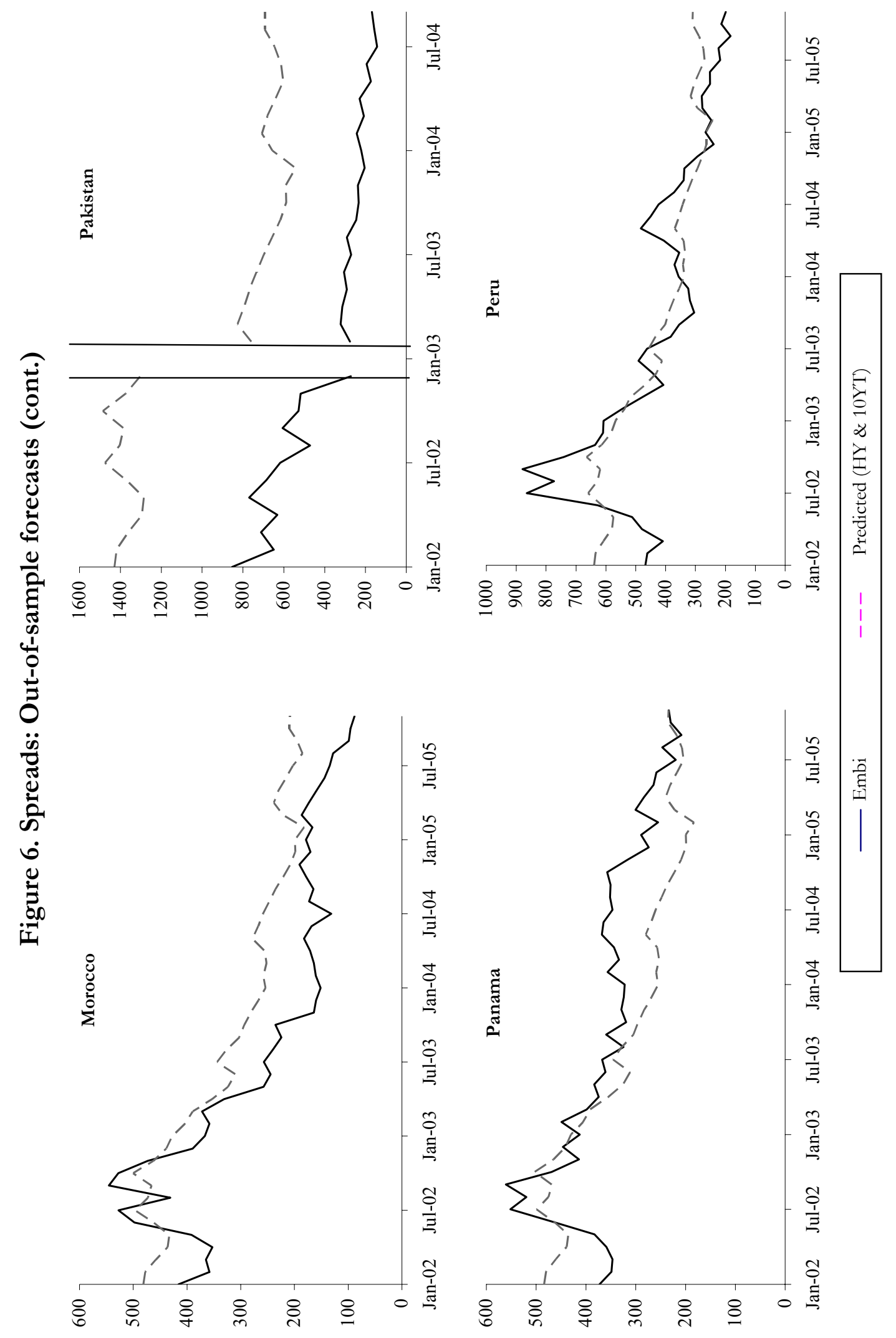




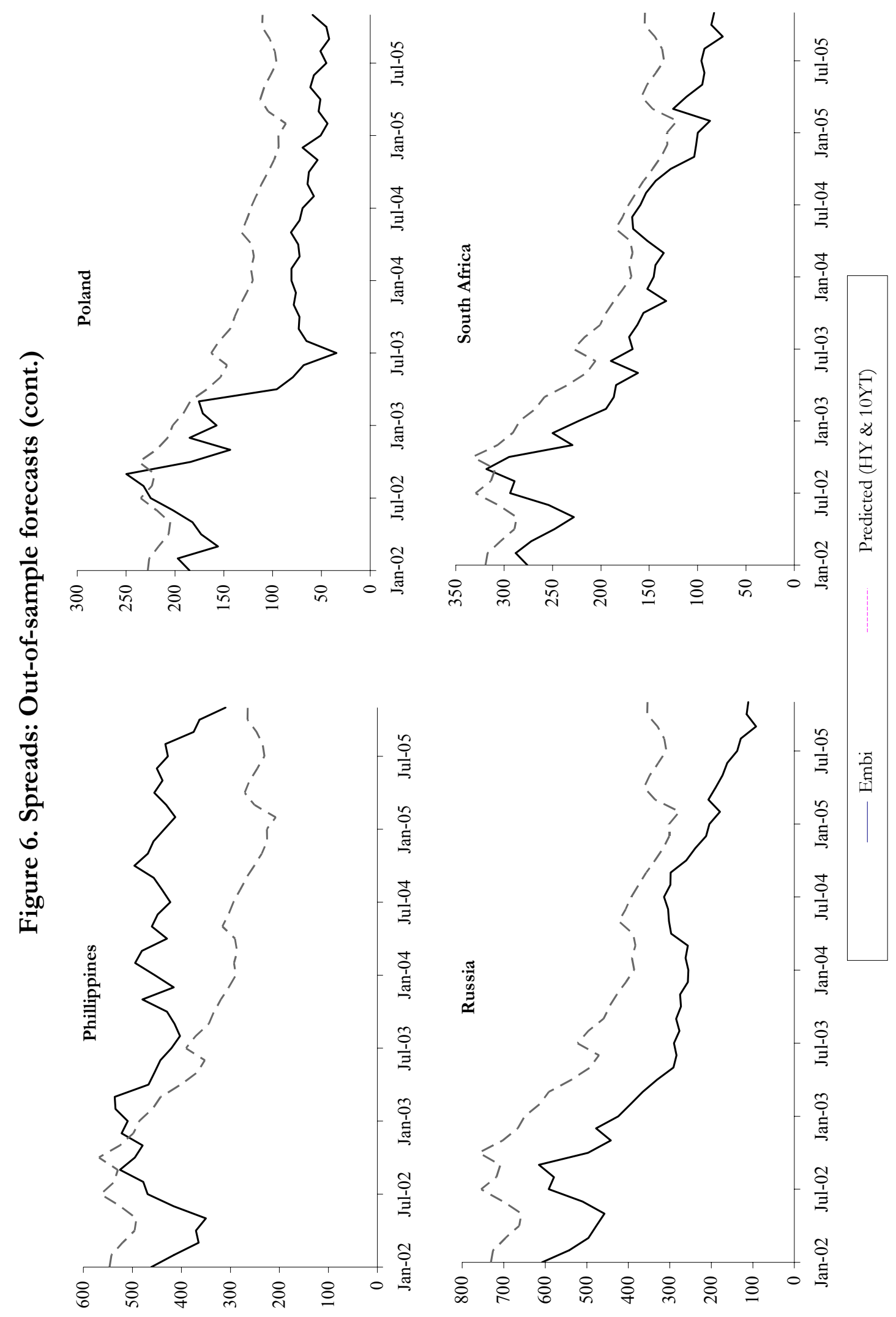




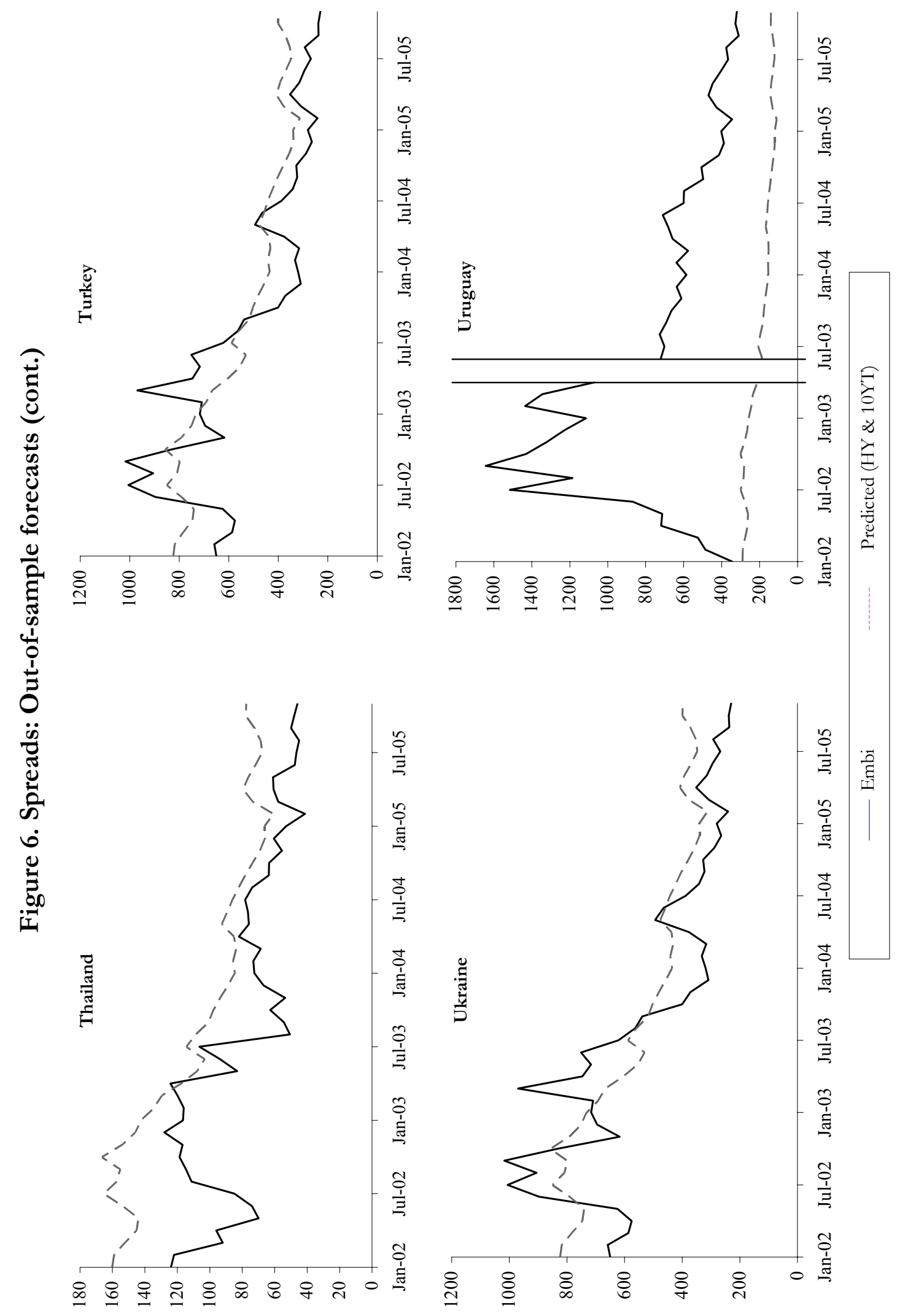




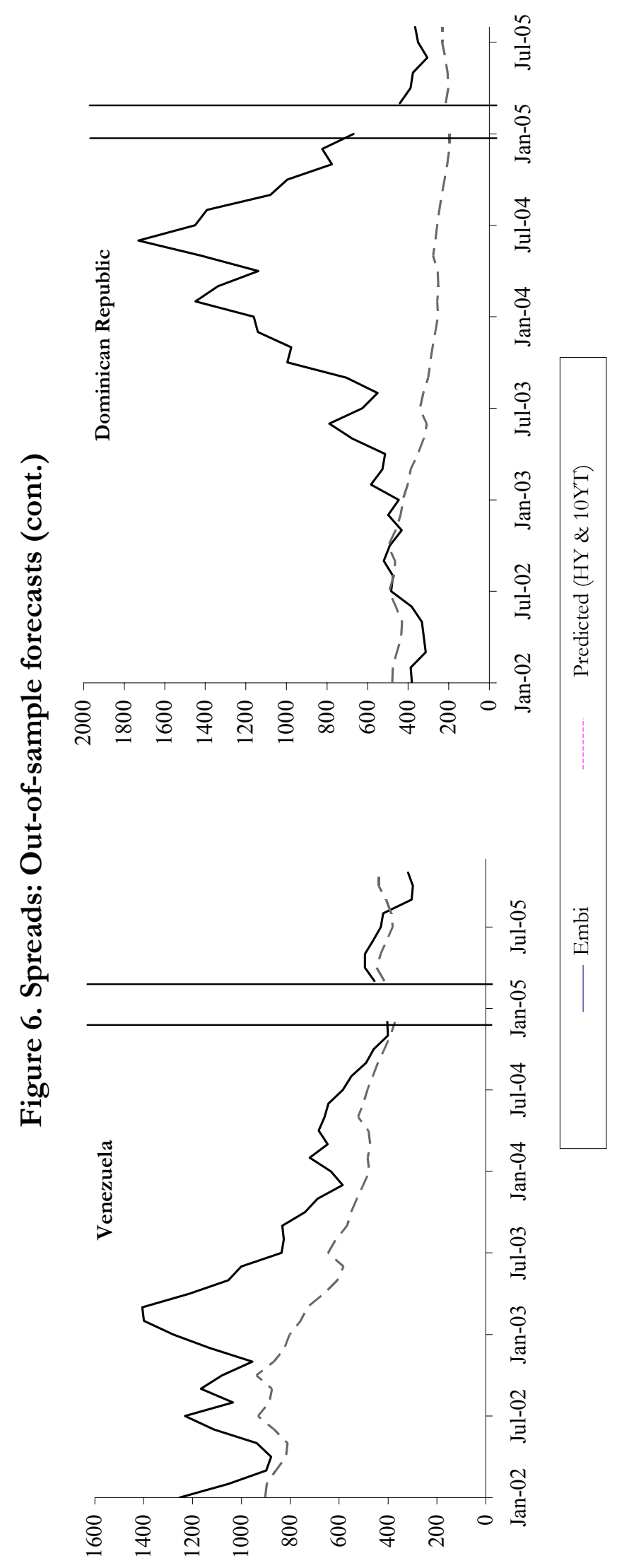


Figure 7. Predicting Argentine spreads (basis points)

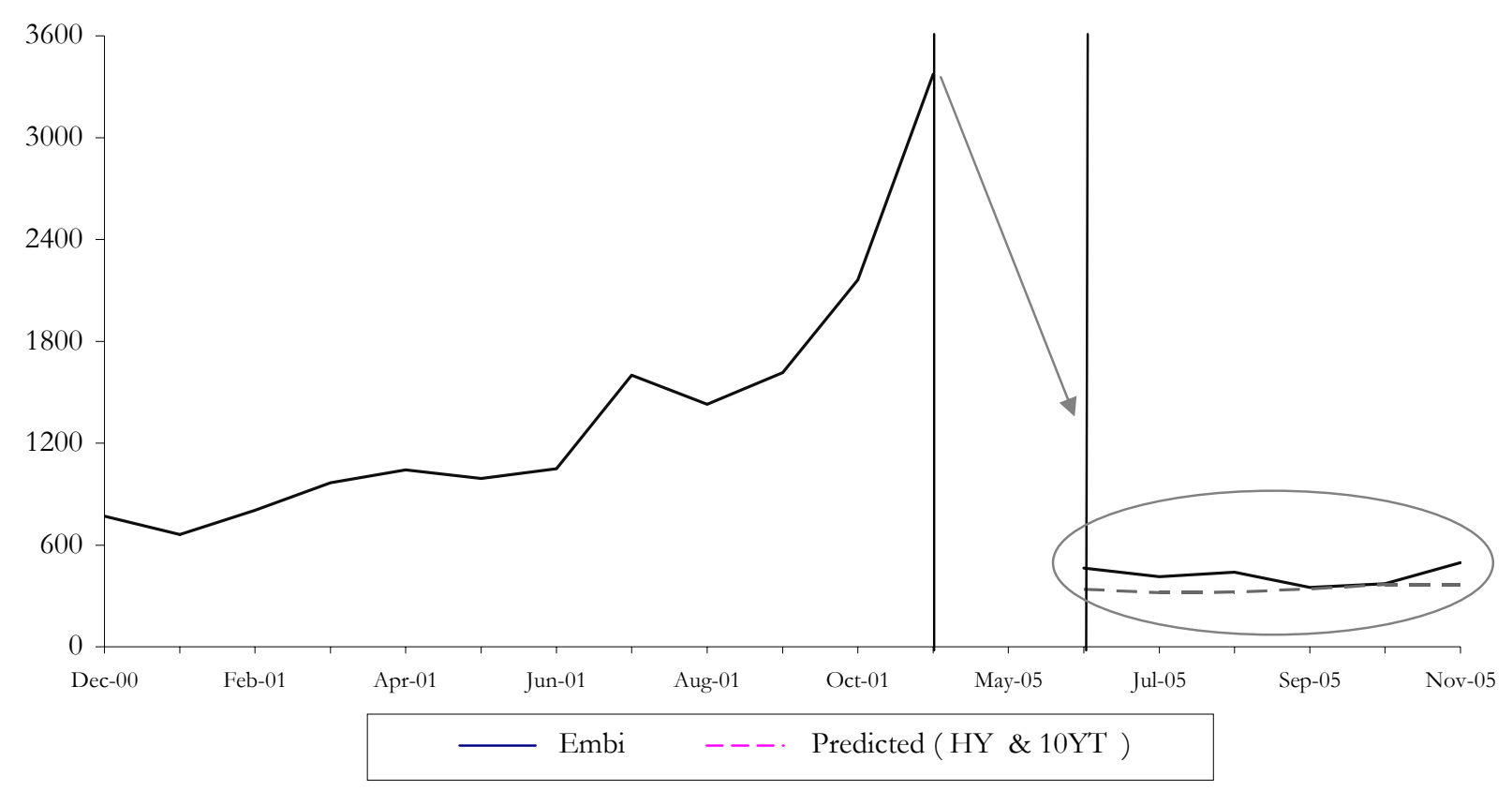




\section{References}

Calvo, G., L. Leiderman, and C. Reinhart (1993). Capital Inflows and Real Exchange Rate Appreciation in Latin America. IMF Staff Papers 40(1) pp. 108-151.

Calvo, G. and E. Talvi (2004). Sudden Stops, Financial Factors and Economic Collapse in Latin America: Learning from Argentina and Chile. NBER Working Paper No. 11153.

Choi, I. (2001). Unit Root Tests for Panel Data. Journal of International Money and Finance, 20: 249-272.

Engle, Robert F. and C. W. J. Granger (1987). Co-integration and Error Correction: Representation, Estimation, and Testing. Econometrica, 55, 251-276.

Fisher, R. A. (1932), Statistical Methods for Research Workers. Oliver and Boyd, Edinburgh 4th Ed.

García Herrero, A. and A. Ortiz (2004). The Role of Global Risk Aversion in Explaining Latin American Sovereign Spreads. Mimeo, Bank of Spain.

Grandes, M. (2003). Convergence and Divergence of Sovereign Bond Spreads: Theory and Facts from Latin America. Delta, ENS/EHESS, Paris.

Herrera, S and G. Perry (2002). Determinants of Latin spreads in the new economy era: the role of US interest rates and other external variables. The World Bank, mimeo.

Levy Yeyati, E. and F. Sturzenegger (2000). Implications of the Euro for Latin America's Financial and Banking Sectors. Emerging Markets Review, Vol 1(1), pp. 53-81.

Maddala, G. S. and S. Wu (1999). A Comparative Study of Unit Root Tests with Panel Data and A New Simple Test. Oxford Bulletin of Economics and Statistics, 61, 631-52.

Mora, N. (2004). Sovereign Credit Ratings: Guilty beyond Reasonable Doubt? Mimeo, American University of Beirut. 


\section{Appendix}

\section{Table A1. Variable definitions and sources}

\begin{tabular}{lll}
\hline Name & Description & Source \\
\hline embi & JP Morgan EMBI global index blended spread, in bps & Datastream \\
HY & CSFB high yield global index, USD, long term debt, in bps & Bloomberg \\
$10 Y T$ & US Treasury notes, 10 year constant maturity yield, bps & U.S. Treasury \\
rating & S\&P rating, long term debt, end of period, foreign currency & S\&P \\
Vix & CBOE Volatility Index & CBOE \\
rating+outlook & S\&P rating augmented using the S\&P outlook. Long term & S\&P \\
& debt, end of period, foreign currency & JP Morgan \\
Rating $(\mathrm{HY})$ & Weighted average rating of issues included in JP Morgan high & yield global index \\
\hline
\end{tabular}


Table A2. Countries and periods covered

\begin{tabular}{|c|c|c|c|c|c|c|}
\hline \multirow[t]{2}{*}{ Country } & \multicolumn{3}{|c|}{ Monthly } & \multicolumn{3}{|c|}{ Weekly } \\
\hline & obs & begins & ends & obs & begins & ends \\
\hline Argentina & 101 & $12 / 31 / 93$ & $11 / 30 / 05$ & 307 & $7 / 4 / 96$ & $11 / 24 / 05$ \\
\hline Brazil & 132 & $12 / 31 / 94$ & $11 / 30 / 05$ & 493 & $7 / 4 / 96$ & $11 / 24 / 05$ \\
\hline Bulgaria & 85 & $11 / 30 / 98$ & $11 / 30 / 05$ & 368 & $11 / 26 / 98$ & $11 / 24 / 05$ \\
\hline China & 141 & $3 / 31 / 94$ & $11 / 30 / 05$ & 493 & $7 / 4 / 96$ & $11 / 24 / 05$ \\
\hline Chile & 79 & $5 / 31 / 99$ & $11 / 30 / 05$ & 341 & $6 / 3 / 99$ & $11 / 24 / 05$ \\
\hline Colombia & 106 & $2 / 28 / 97$ & $11 / 30 / 05$ & 458 & $3 / 6 / 97$ & $11 / 24 / 05$ \\
\hline Croatia & 89 & $1 / 31 / 97$ & $5 / 31 / 04$ & 388 & $1 / 23 / 97$ & $6 / 24 / 04$ \\
\hline Dominican Republic & 45 & $11 / 30 / 01$ & $11 / 30 / 05$ & 189 & $12 / 6 / 01$ & $11 / 24 / 05$ \\
\hline Ecuador & 64 & $8 / 31 / 00$ & $11 / 30 / 05$ & 276 & $8 / 31 / 00$ & $11 / 24 / 05$ \\
\hline Egypt & 53 & $7 / 31 / 01$ & $11 / 30 / 05$ & 228 & $8 / 2 / 01$ & $11 / 24 / 05$ \\
\hline El Salvador & 44 & $4 / 30 / 02$ & $11 / 30 / 05$ & 189 & $5 / 2 / 02$ & $11 / 24 / 05$ \\
\hline Hungary & 83 & $1 / 31 / 99$ & $11 / 30 / 05$ & 358 & $2 / 4 / 99$ & $11 / 24 / 05$ \\
\hline Indonesia & 19 & $5 / 31 / 04$ & $11 / 30 / 05$ & 80 & $6 / 3 / 04$ & $11 / 24 / 05$ \\
\hline Korea & 124 & $12 / 31 / 93$ & $3 / 31 / 04$ & 409 & $7 / 4 / 96$ & $4 / 29 / 04$ \\
\hline Lebanon & 92 & $4 / 30 / 98$ & $11 / 30 / 05$ & 398 & $4 / 30 / 98$ & $11 / 24 / 05$ \\
\hline Malaysia & 110 & $10 / 31 / 96$ & $11 / 30 / 05$ & 476 & $10 / 31 / 96$ & $11 / 24 / 05$ \\
\hline Mexico & 144 & $12 / 31 / 93$ & $11 / 30 / 05$ & 493 & 7/4/96 & $11 / 24 / 05$ \\
\hline Morocco & 93 & $3 / 31 / 98$ & $11 / 30 / 05$ & 406 & $3 / 5 / 98$ & $11 / 24 / 05$ \\
\hline Pakistan & 39 & $6 / 30 / 01$ & $11 / 30 / 05$ & 168 & $7 / 5 / 01$ & $11 / 24 / 05$ \\
\hline Panama & 107 & $1 / 31 / 97$ & $11 / 30 / 05$ & 464 & $1 / 23 / 97$ & $11 / 24 / 05$ \\
\hline Peru & 96 & $12 / 31 / 97$ & $11 / 30 / 05$ & 417 & $12 / 18 / 97$ & $11 / 24 / 05$ \\
\hline Philippines & 96 & $12 / 31 / 97$ & $11 / 30 / 05$ & 415 & $1 / 1 / 98$ & $11 / 24 / 05$ \\
\hline Poland & 126 & $6 / 30 / 95$ & $11 / 30 / 05$ & 493 & $7 / 4 / 96$ & $11 / 24 / 05$ \\
\hline Russia & 73 & $12 / 31 / 97$ & $11 / 30 / 05$ & 317 & $1 / 1 / 98$ & $11 / 24 / 05$ \\
\hline South Africa & 132 & $12 / 31 / 94$ & $11 / 30 / 05$ & 493 & $7 / 4 / 96$ & $11 / 24 / 05$ \\
\hline Thailand & 103 & $5 / 31 / 97$ & $11 / 30 / 05$ & 445 & $6 / 5 / 97$ & $11 / 24 / 05$ \\
\hline Tunisia & 43 & $5 / 31 / 02$ & $11 / 30 / 05$ & 184 & $6 / 6 / 02$ & $11 / 24 / 05$ \\
\hline Turkey & 114 & $6 / 30 / 96$ & $11 / 30 / 05$ & 493 & $7 / 4 / 96$ & $11 / 24 / 05$ \\
\hline Ukraine & 48 & $12 / 31 / 01$ & $11 / 30 / 05$ & 207 & $12 / 27 / 01$ & $11 / 24 / 05$ \\
\hline Uruguay & 54 & $5 / 31 / 01$ & $11 / 30 / 05$ & 235 & $5 / 31 / 01$ & $11 / 24 / 05$ \\
\hline Venezuela & 142 & $12 / 31 / 93$ & $11 / 30 / 05$ & 487 & $7 / 4 / 96$ & $11 / 24 / 05$ \\
\hline
\end{tabular}


Table A3. Changes in Emerging Market Spreads

(monthly sample; in percent)

\begin{tabular}{|c|c|c|c|c|c|c|c|}
\hline Country name & $\overline{\mathrm{N}}$ & mean & median & StdDev & $\min$ & $\max$ & skewness \\
\hline Argentina & 100 & 0.0323 & -0.0288 & -0.0288 & -0.9224 & 1.8330 & 2.8299 \\
\hline Brazil & 132 & 0.0081 & -0.0285 & -0.0285 & -0.3038 & 1.3377 & 3.3149 \\
\hline Bulgaria & 85 & -0.0203 & -0.0182 & -0.0182 & -0.2589 & 0.3868 & 0.5952 \\
\hline China & 140 & 0.0050 & -0.0039 & -0.0039 & -0.3950 & 1.2595 & 3.8404 \\
\hline Chile & 78 & -0.0058 & -0.0156 & -0.0156 & -0.3064 & 0.4615 & 0.9362 \\
\hline Colombia & 105 & 0.0162 & -0.0044 & -0.0044 & -0.2270 & 0.9533 & 2.3593 \\
\hline Croatia & 89 & 0.0088 & -0.0038 & -0.0038 & -0.3658 & 0.8098 & 1.7101 \\
\hline Dominican Republic & 44 & 0.0121 & -0.0228 & -0.0228 & -0.2251 & 0.4139 & 0.5240 \\
\hline Ecuador & 64 & -0.0145 & -0.0275 & -0.0275 & -0.5292 & 0.4101 & -0.0632 \\
\hline Egypt & 52 & -0.0197 & -0.0626 & -0.0626 & -0.4072 & 0.5973 & 1.0675 \\
\hline El Salvador & 43 & -0.0009 & 0.0093 & 0.0093 & -0.1478 & 0.1859 & 0.2228 \\
\hline Hungary & 82 & 0.0875 & -0.0191 & -0.0191 & -0.7516 & 2.4406 & 2.2840 \\
\hline Indonesia & 18 & -0.0183 & -0.0616 & -0.0616 & -0.1608 & 0.3370 & 1.2757 \\
\hline Korea & 123 & 0.0224 & -0.0122 & -0.0122 & -0.3430 & 1.7783 & 3.6450 \\
\hline Lebanon & 91 & 0.0088 & 0.0000 & 0.0000 & -0.2466 & 0.5957 & 1.0699 \\
\hline Malaysia & 109 & 0.0141 & -0.0063 & -0.0063 & -0.3654 & 0.7263 & 1.2197 \\
\hline Mexico & 143 & 0.0068 & -0.0256 & -0.0256 & -0.2435 & 1.0460 & 2.9420 \\
\hline Morocco & 93 & 0.0056 & -0.0248 & -0.0248 & -0.4047 & 2.4837 & 6.4947 \\
\hline Pakistan & 37 & -0.0429 & -0.0509 & -0.0509 & -0.4762 & 0.3381 & 0.0169 \\
\hline Panama & 107 & 0.0040 & -0.0078 & -0.0078 & -0.3516 & 0.7682 & 2.1712 \\
\hline Peru & 96 & 0.0014 & -0.0384 & -0.0384 & -0.1921 & 0.8272 & 2.0001 \\
\hline Philippines & 95 & 0.0066 & -0.0096 & -0.0096 & -0.3008 & 1.2363 & 5.1035 \\
\hline Poland & 126 & -0.0023 & -0.0238 & -0.0238 & -0.4931 & 1.2043 & 2.5033 \\
\hline Russia & 72 & 0.0220 & -0.0401 & -0.0401 & -0.2868 & 2.8362 & 7.0379 \\
\hline South Africa & 131 & 0.0046 & -0.0365 & -0.0365 & -0.2671 & 1.1714 & 3.1456 \\
\hline Thailand & 102 & 0.0207 & -0.0151 & -0.0151 & -0.5235 & 1.6069 & 3.3475 \\
\hline Tunisia & 42 & -0.0096 & -0.0500 & -0.0500 & -0.4465 & 1.0948 & 2.6051 \\
\hline Turkey & 113 & 0.0199 & -0.0326 & -0.0326 & -0.2744 & 2.0647 & 5.1150 \\
\hline Ukraine & 48 & -0.0274 & -0.0656 & -0.0656 & -0.3569 & 0.3203 & 0.2740 \\
\hline Uruguay & 53 & 0.0214 & -0.0260 & -0.0260 & -0.2170 & 0.7433 & 1.5831 \\
\hline Venezuela & 141 & 0.0116 & -0.0165 & -0.0165 & -0.3773 & 2.0324 & 5.3668 \\
\hline
\end{tabular}

